Ling-Li Zhang, Eric Delpire and Noga Vardi

J Neurophysiol 98:266-277, 2007. doi:10.1152/jn.00288.2007

You might find this additional information useful...

Supplemental material for this article can be found at:

http://jn.physiology.org/cgi/content/full/00288.2007/DC1

This article cites 56 articles, 25 of which you can access free at:

http://jn.physiology.org/cgi/content/full/98/1/266\#BIBL

Updated information and services including high-resolution figures, can be found at:

http://jn.physiology.org/cgi/content/full/98/1/266

Additional material and information about Journal of Neurophysiology can be found at:

http://www.the-aps.org/publications/jn

This information is current as of July 31, 2007 . 


\title{
NKCC1 Does Not Accumulate Chloride in Developing Retinal Neurons
}

\author{
Ling-Li Zhang, ${ }^{1}$ Eric Delpire, ${ }^{2}$ and Noga Vardi ${ }^{1}$ \\ ${ }^{1}$ Department of Neuroscience, University of Pennsylvania, Philadelphia, Pennsylvania; and ${ }^{2}$ Department of Anesthesiology, \\ Vanderbilt University Medical Center, Nashville, Tennessee
}

Submitted 14 March 2007; accepted in final form 8 May 2007

Zhang L-L, Delpire E, Vardi N. NKCC1 does not accumulate chloride in developing retinal neurons. J Neurophysiol 98: 266-277, 2007. First published May 9, 2007; doi:10.1152/jn.00288.2007. GABA excites immature neurons due to their relatively high intracellular chloride concentration. This initial high concentration is commonly attributed to the ubiquitous chloride cotransporter NKCC1, which uses a sodium gradient to accumulate chloride. Here we tested this hypothesis in immature retinal amacrine and ganglion cells. Western blotting detected NKCC1 at birth and its expression first increased, then decreased to the adult level. Immunocytochemistry confirmed this early expression of NKCC1 and localized it to all nuclear layers. In the ganglion cell layer, staining peaked at P4 and then decreased with age, becoming undetectable in adult. In comparison, $\mathrm{KCC} 2$, the chloride extruder, steadily increased with age localizing primarily to the synaptic layers. For functional tests, we used calcium imaging with fura-2 and chloride imaging with 6-methoxy$\mathrm{N}$-ethylquinolinium iodide. If NKCC1 accumulates chloride in ganglion and amacrine cells, deleting or blocking it should abolish the GABA-evoked calcium rise. However, at P0-5 GABA consistently evoked a calcium rise that was not abolished in the NKCC1-null retinas, nor by applying high concentrations of bumetanide (NKCC blocker) for long periods. Furthermore, intracellular chloride concentration in amacrine and ganglion cells of the NKCC1-null retinas was $\sim 30 \mathrm{mM}$, same as in wild type at this age. This concentration was not lowered by applying bumetanide or by decreasing extracellular sodium concentration. Costaining for NKCC1 and cellular markers suggested that at P3, NKCC1 is restricted to Müller cells. We conclude that NKCC1 does not serve to accumulate chloride in immature retinal neurons, but it may enable Müller cells to buffer extracellular chloride.

\section{N T R O D U C T I O N}

During brain and retinal development, GABA's action shifts from excitatory to inhibitory (Ben Ari 2001, 2002; Catsicas and Mobbs 2001; Fischer et al. 1998; Sernagor et al. 2003; Stellwagen et al. 1999; Zhang et al. 2006b; Zhou 2001). This shift results from a decline of intracellular chloride concentration from $\sim 30$ to $\sim 15 \mathrm{mM}$ which reduces the chloride equilibrium potential $\left(E_{\mathrm{Cl}}\right)$ from above to below the resting potential $\left(E_{\text {rest }}\right)$ (Zhang et al. 2006b). Maintaining an equilibrium potential different from the resting potential requires an active transport of chloride: extrusion for $E_{\mathrm{Cl}}<E_{\text {rest }}$ and accumulation for $E_{\mathrm{Cl}}>E_{\text {rest }}$.

The extruder is probably the neuron-specific $\mathrm{K}^{+}-\mathrm{Cl}^{-}$cotransporter, $\mathrm{KCC} 2$. This transporter normally extrudes chloride with the outward potassium gradient (Payne et al. 1996), and evidence supporting its function as the main chloride extruder is strong. It upregulates during development ( $\mathrm{Li}$ et al. 2002; Vu

\footnotetext{
Address for reprint requests and other correspondence: N. Vardi, Dept. of Neuroscience, University of Pennsylvania, Philadelphia, PA 19104-6058 (E-mail: noga@ retina.anatomy.upenn.edu). ${ }^{1}$ The on-line version of this article contains supplemental data.
}

et al. 2000; Zhang et al. 2006a), and in adult, it broadly localizes to GABA-receptive neurons ( $\mathrm{Li}$ et al. 2002; Lu et al. 1999; Vardi et al. 2000; Williams et al. 1999). Additionally, pharmacological blockade, gene deletion, or inhibition of expression with siRNA, all result in a higher than normal $E_{\mathrm{Cl}}$ (Balakrishnan et al. 2003; DeFazio et al. 2000; Gulacsi et al. 2003; Hubner et al. 2001; Jarolimek et al. 1999; Rivera et al. 1999; Zhu et al. 2005).

The accumulator is thought to be the ubiquitous $\mathrm{Na}^{+}-\mathrm{K}^{+}$$\mathrm{Cl}^{-}$cotransporter NKCC1, which uses the inward sodium gradient to accumulate chloride along with sodium and potassium (reviewed by Russell 2000). The evidence supporting $\mathrm{NKCC} 1$ as the chloride accumulator in certain mature neurons is good. NKCC1 localizes to neurons known to maintain high intracellular chloride such as olfactory epithelial cells and retinal horizontal cells (Reisert et al. 2005; Vardi et al. 2000); the olfactory epithelial cells in the NKCC1-null mouse show a reduced calcium-activated inward chloride current due to reduced intracellular chloride (Reisert et al. 2005), and in dorsal root ganglion cells, blocking NKCC1 with bumetanide, manipulating sodium concentrations, or deleting the gene encoding NKCC1 reduces intracellular chloride concentrations (Rohrbough and Spitzer 1996; Sung et al. 2000).

In contrast, evidence supporting NKCC1 as the chloride accumulator in immature neurons is weak and relies mostly on the downregulation of NKCC1 mRNA and protein during development (Ikeda et al. 2003; Kanaka et al. 2001; Li et al. 2002; Mikawa et al. 2002; Plotkin et al. 1997b). Functional experiments were only performed in neocortex where the downward shift of high $E_{\mathrm{Cl}}$ with bumetanide was correlated with NKCC1 mRNA expression (Yamada et al. 2004). No study has utilized the NKCC1 knockout mouse to test the transporter's function in early development except for its effect on epileptic seizure (Dzhala et al. 2005). Here we show that in immature retinal amacrine and ganglion cells, NKCC1 blockade or deletion does not affect intracellular chloride. Furthermore, in the first postnatal week, NKCC1 appears to be restricted to Müller cells, and is probably not localized to any retinal neurons.

\section{METHODS}

\section{Western blotting}

Newborn mice were deeply anesthetized on postnatal days P0 (date of birth) to P6 with halothane and killed by decapitation. Older mice were deeply anesthetized with an intraperitoneal injection of ketamine $(85 \mu \mathrm{g} / \mathrm{gm})$ and xylazine (13

\footnotetext{
The costs of publication of this article were defrayed in part by the payment of page charges. The article must therefore be hereby marked "advertisement" in accordance with 18 U.S.C. Section 1734 solely to indicate this fact.
} 
$\mu \mathrm{g} / \mathrm{gm})$ followed by anesthetic overdose. Animals were treated in compliance with federal regulations and University of Pennsylvania policy. Retinas were collected into two developmental series,: series 1: P0, 3, 5, 8, 12, 14, 24, and adult ( $>3 \mathrm{mo}$ ) and series 2 : P0 , 3, 5, 9, 12, 16, and adult. For ages younger than $\mathrm{P} 5$, retinas from two to three littermates were combined. Retinas were frozen immediately with liquid $\mathrm{N}_{2}$ and stored at $-80^{\circ} \mathrm{C}$. Retinas from each series were processed in parallel: they were homogenized in $0.2-1 \mathrm{ml}$ ice-cold homogenization buffer [ $5 \mathrm{ml} / \mathrm{g}$ wet weight; containing (in $\mathrm{mM}$ ): 320 sucrose, 5 Tris, 5 Tris- $\mathrm{HCl}$, and 2 EDTA, $2.5 \beta$-mercaptoethanol, $\mathrm{pH}$ adjusted to 7.4 at room temperature] containing protease inhibitor cocktails (P8340; Sigma Aldrich, St. Louis, MO), and the homogenates were centrifuged at $6,000 \mathrm{~g}$ for $10 \mathrm{~min}$ at $4^{\circ} \mathrm{C}$ to remove debris.

Equal amounts of protein $(10 \mu \mathrm{g})$ from each age of a developmental series were mixed with NuPAGE LDS sample buffer (Invitrogen, Carlsbad, CA), incubated for $45 \mathrm{~min}$ at $37^{\circ} \mathrm{C}$, then loaded onto 5.0 or $7.5 \%$ Tris-glycine gel (Bio-Rad). Electrophoresis was performed with a mini-protean II electrophoresis cell (Bio-Rad) under reduced denaturing conditions. The resolved proteins were transferred to a polyvinylidene difluoride (PVDF) membrane (Bio-Rad) in transfer buffer (192 $\mathrm{mM}$ glycine, $25 \mathrm{mM}$ Tris-Cl, $\mathrm{pH} 8.3$, and $20 \%$ methanol) for 40-50 min at $15 \mathrm{~V}$ using a Bio-Rad Trans-Blot semi-dry transfer cell. The membrane was blocked with $5-7 \%$ skim milk in TBS-T $(10 \mathrm{mM}$ Tris-HCl, $150 \mathrm{mM} \mathrm{NaCl}, 0.1 \%$ Tween 20 , $\mathrm{PH}$ 7.4) for $1 \mathrm{~h}$, and incubated with the primary antibody overnight at $4^{\circ} \mathrm{C}$ in TBS-T-milk. After extensive washes, the membrane was incubated with the secondary antibody (antirabbit Fab fragments linked to HRP, Protos, Burlingame, CA) in TBS-T-milk for $2 \mathrm{~h}$ at room temperature. After extensive washes in TBS-T, bound antibody was detected by enhanced chemiluminescence (Pierce, Rockford, IL).

In certain experiments, comparison of $\mathrm{NKCC} 1$ and $\mathrm{KCC} 2$ expression was done on the same blot. In these experiments, we removed the antibodies from the membrane with a stripping buffer (Pierce, Rockford, IL) and re-probed the membrane with a second antibody. The transporter patterns detected after the first probe was stripped and a second probe applied were similar to those with the fresh probe, but the intensity was reduced. Thus only the freshly probed blots were included in our quantification.

For quantification, chemiluminescence was captured within 20 min of the reaction using a Kodak Imaging Station 440CF system (with a 12-bit cooled CCD camera) and the result was quantified using Kodak 1D imaging analysis software (Sunnyvale, CA). Control experiments have shown that detection of protein is linearly proportional to the amount of protein in this assay. Exposures of each blot were adjusted to ensure that all signals were within the linear range. After subtracting background intensity from each pixel, we summed all the signals within a band to give the net band intensity. For Display, the 12-bit chemiluminescence imaging data were converted to 8-bit after a linear transform with saturation at the high intensities to allow visibility of the low-intensity bands.

\section{Immunostaining}

Eyecups from several littermates were grouped into the following postnatal ages, series 1: $0,1,3,5,7,13$, and 20 and series $2: 0,2,5,7,10,12,16$, and 18 . For intensity compari- sons, eyecups were immersion-fixed for $1 \mathrm{~h}$ at room temperature in $4 \%$ paraformaldehyde and $0.01 \%$ glutaraldehyde diluted in $0.1 \mathrm{M}$ phosphate buffer at $\mathrm{pH}$ 7.4. For the rest of the immunostaining experiments, fixation varied between 2 and $4 \%$ paraformaldehyde fixed for $10-60 \mathrm{~min}$. Retinas were cryoprotected with $30 \%$ sucrose in phosphate buffer (overnight at $4^{\circ} \mathrm{C}$ ). Eyes were then frozen in a mixture of Tissue Freezing Medium (Electron Microscopy Sciences, Ft. Washington, PA) and 20\% sucrose (1:2), and cryosectioned vertically in 10- $\mu \mathrm{m}$ sections. Cryosections were stained according to a standard protocol: soak in diluent containing $0.1 \mathrm{M}$ phosphate buffer, $10 \%$ normal goat serum, $5 \%$ sucrose, and $0.3 \%$ Triton X-100; incubate in primary antibody overnight at $4{ }^{\circ} \mathrm{C}$; wash and incubate in secondary antibody for $3 \mathrm{~h}$ at room temperature. Sections were mounted in Vectashield (Vector Laboratories, Burlingame, CA) and visualized with a confocal microscope (Leica, Nussloch, Germany). In double-labeling experiments, sections were incubated with a mixture of primary antibodies followed by a mixture of secondary antibodies.

To examine NKCC1 localization at the electron microscope level, fixed tissue was frozen and thawed three times prior to Vibratome sectioning (100 $\mu \mathrm{m}$ thick). Sections were incubated in diluent and primary antibody as in the preceding text (stain was invisible with $<0.3 \%$ Triton $\mathrm{X}-100$ ), then in secondary antibody conjugated to HRP. They were then rinsed, developed in $0.05 \% 3,3^{\prime}$-diaminobenzidine (DAB) $+0.01 \%$ hydrogen peroxide in phosphate buffer for $15 \mathrm{~min}$, washed, and postfixed. DAB reaction product was intensified with gold-substituted silver and sections were osmicated, dehydrated, and mounted in Epon 812. Ultrathin sections were poststained with uranyl acetate. Primary antibodies are listed in Table 1. Secondary antibodies: for single labeling, we used anti-rabbit and anti-mouse conjugated to FITC, and for double labeling, we also used anti-rabbit and anti-mouse conjugated to rhodamine or to Cy3. All secondary antibodies were from Jackson ImmunoResearch (West Grove, PA).

\section{Calcium imaging}

A retina was cleaned of vitreous, detached from the pigment epithelium, and cut into two to three pieces. Retinal pieces were mounted on a filter paper and maintained in bicarbonatebased Ames medium saturated with carbogen $\left(95 \% \quad \mathrm{O}_{2}-5 \%\right.$ $\mathrm{CO}_{2}$ ). In young mice (P0-P6), ganglion cells were often exposed when detaching the vitreous; in older mice, ganglion cells were exposed by gently scratching the vitreal surface with a scalpel tip or a brush. This procedure ensured that fluorescence was collected cleanly from ganglion and amacrine cells somas (Zhou 2001). Retinal pieces were loaded in 5-10 $\mu \mathrm{M}$ fura-2 AM (Molecular Probes; Eugene, OR) in oxygenated Ames medium for $1 \mathrm{~h}$ at $27-30^{\circ} \mathrm{C}$. A retina was placed in an optical recording chamber mounted on a fixed-stage, upright microscope (Olympus BX51WI) and continuously superfused (3-4 $\mathrm{ml} / \mathrm{min}$ ) with Ames medium preheated to $30-33^{\circ} \mathrm{C}$. Fura-2 was excited alternately at 340 and $380 \mathrm{~nm}$ with a xenon arc lamp in lambda DG4 (Sutter Instrument; Novato, CA) and was attenuated with a neutral density filter $(0.25)$. Fluorescent images were viewed with a $\times 40$ water-immersion lens (NA, 0.8 , Olympus; Tokyo, Japan), filtered with a 510/40 nm emission filter (set 71000, Chroma; Rockingham, VT), and captured with a Hamamatsu Orca II ER digital CCD camera (C4742- 
TABLE 1. Antibody list

\begin{tabular}{|c|c|c|c|c|}
\hline Molecule & Species, Antigen, Clone* & Host & $\begin{array}{l}\text { Source of Antibody } \\
\text { (Catalog Number) }\end{array}$ & Dilution $\dagger$ \\
\hline NKCC & $\begin{array}{l}\text { Human, CT-aa 902-1212 (T4; } \\
\text { recognizes NKCC1 + NKCC2) }\end{array}$ & Mouse monoclonal & Hybridoma Bank, Iowa City, IA & $1: 500$ \\
\hline NKCC1 & Mouse, CT-aa 938-1011 & Rabbit polyclonal & E. Delpire, Nashville, Tennessee & $1: 20-1: 150$ \\
\hline $\mathrm{KCC} 2$ & Rat, CT - 112 last aa & Rabbit polyclonal & $\begin{array}{l}\text { Cell Signaling Solutions, Lake } \\
\text { Placid, NY }\end{array}$ & $1: 300$ \\
\hline GFAP (Glia fibrilary acidic protein) & Bovine, Glial filaments & Rat monoclonal & $\begin{array}{l}\text { Virginia Lee, University of } \\
\text { Pennsylvania, Philadelphia. PA }\end{array}$ & $1: 50$ \\
\hline Parvalbumin & Carp, Muscle (PA-235) & Mouse monoclonal & Sigma, St Louis, MO; (P 3171) & $1: 2000$ \\
\hline Recoverin & Bovine Purified whole protein & Rabbit polyclonal & $\begin{array}{l}\text { Alexander Dizhoor, Pennsylvania } \\
\text { College of Optometry, Elkins } \\
\text { Park, PA; code: P26 }\end{array}$ & $1: 500$ \\
\hline $\operatorname{PKC} \alpha$ & Bovine, Purified protein (MC5) & Mouse monoclonal & Sigma, St Louis, MO; (P 5704) & $1: 50$ \\
\hline GABA & GABA coupled to KLH & Guinea pig & $\begin{array}{l}\text { Chemicon International Inc., } \\
\text { Temecula, CA; (AB175) }\end{array}$ & $1: 2000$ \\
\hline $\mathrm{G} \alpha_{\mathrm{o}}$ & Bovine, Purified from brain & Mouse monoclonal & $\begin{array}{l}\text { Chemicon International Inc., } \\
\text { Temecula, CA; (MAB 3073) }\end{array}$ & $1: 500$ \\
\hline $\mathrm{G} \gamma 13$ & $\begin{array}{l}\text { Mouse, peptide } \\
\text { CFLNPDLMKNNPWV }\end{array}$ & Rabbit polyclonal & $\begin{array}{l}\text { Robert Margolskee, Mount Sinai, } \\
\text { New York, NY }\end{array}$ & $1: 500$ \\
\hline Neurofilaments & $\begin{array}{l}\text { Porcine, Neurofilament } 68 \mathrm{kDa} \\
\text { (DA2) }\end{array}$ & Mouse monoclonal & $\begin{array}{l}\text { Novocostra, Newcastle upon Tyne, } \\
\text { UK; (NCL-NF68-DA2) }\end{array}$ & $1: 200$ \\
\hline ChAT & Rat, Purified from brain & Mouse monoclonal & $\begin{array}{l}\text { Chemicon International Inc., } \\
\text { Temecula, CA; (MAB 305) }\end{array}$ & $1: 200$ \\
\hline GS (glutamine synthetase) & Sheep, Purified protein & Mouse monoclonal & BD BioSciences, San Jose, CA & $1: 250$ \\
\hline Vimentin & Human, C-terminus AA 438-459 & Rabbit polyclonal & $\begin{array}{l}\text { Virginia Lee, University of } \\
\text { Pennsylvania, Philadelphia, PA }\end{array}$ & $1: 2000$ \\
\hline
\end{tabular}

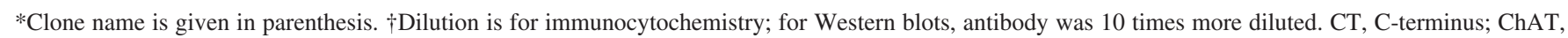
choline-acetyl transferase; PKC, protein kinase C.

98-24ER, Hamamatsu; Hamamatsu city, Japan). Wavelength switch and imaging capture were controlled by Openlab software (Improvision; Lexington, MA) running under Mac G4. To minimize potential UV phototoxicity, the illuminated retinal area was restricted by closing the field aperture to match the CCD imaging field $(216 \times 165 \mu \mathrm{m})$, and the pixels were binned $(2 \times 2)$. Exposure time was $25-200 \mathrm{~ms}$, and sampling interval was $3-4 \mathrm{~s}$.

\section{Determining intracellular chloride with a reference method}

To determine intracellular chloride level, we used the reference methods developed earlier (Zhang et al. 2006b). Briefly, fresh 6-methoxy- $N$-ethyl-1,2-dihydroquinoline (dihydroMEQ) was synthesized from $5 \mathrm{mg}$ 6-methoxy-N-ethylquinolinium iodide (MEQ) according to the protocol provided by Molecular Probe (Eugene, OR). The reduced product was resuspended in dimethyl sulfoxide, and added to Ames medium to yield a loading concentration of $\sim 300 \mu \mathrm{M}$ dihydroMEQ. The concentration of DMSO in the final solution was $<1 \%$. Retinal pieces, prepared as described above, were incubated in oxygenated dihydro-MEQ for $1 \mathrm{~h}$ at $27-30^{\circ} \mathrm{C}$. To identify cells and monitor their volume, $1 \mu \mathrm{M}$ calcein and $0.001 \%-0.02 \%$ pluronic acid were added for the last $15 \mathrm{~min}$ of loading. During loading, intracellular oxidation converted the membrane-permeable dihydro-MEQ into the charged and impermeable MEQ. After loading, retinas were transferred into fresh Ames medium at room temperature and then transferred to the recording chamber. The chamber was maintained at $27-29^{\circ} \mathrm{C}$ (rather than $33^{\circ} \mathrm{C}$ ) to reduce MEQ leakage and increase MEQ sensitivity (Fukuda et al. 1998). This temperature did not affect chloride distribution because similar measurements were obtained with gramicidine-perforated record- ings performed at $35^{\circ} \mathrm{C}$ (Zhang et al. 2006b). The optical setup and acquisition system were the same as that for calcium imaging except that excitation and emission were filtered for MEQ and calcein. Excitation alternated between $345 \mathrm{~nm}$ (D345/10x, Chroma) and $485 \mathrm{~nm}$ (S485/25x, Chroma), and emission was collected with a dual band filter with peaks at 450 and $535 \mathrm{~nm}$ (set 91018, Chroma). Images were collected every 10-15 s. After the unperturbed MEQ fluorescence of cells located at the ganglion cell layer was recorded, the retina was perfused with a reference solution containing $30 \mathrm{mM} \mathrm{Cl}^{-}, 133$ $\mathrm{mM} \mathrm{K}^{+}$(instead of $\mathrm{Na}^{+}$), $14 \mu \mathrm{M} \mathrm{K}^{+} / \mathrm{H}^{+}$exchanger nigericin, and $20 \mu \mathrm{M} \mathrm{Cl}^{-} / \mathrm{OH}^{-}$exchanger tributyltin (Krapf et al. 1988). We chose a $30 \mathrm{mM}$ reference solution because the reference method is most accurate when the reference solution is close to the predicted intracellular solution, and the intracellular solution in young wild-type ganglion cells is close to this value (Zhang et al. 2006b). Cells were then imaged until intracellular chloride concentration equilibrated and the fluorescent remained relatively stable $(\sim 15 \mathrm{~min})$.

\section{Optical signal analysis}

Imaging and statistical analysis were done with Openlab and Excel (Microsoft; Seattle, WA). The time-lapse image stacks were first registered to correct for retinal movements. Then a region of interest was drawn around a dye-loaded ganglion or amacrine cell in the ganglion cell layer, and the cell's fluorescence was measured at each time point. Background due to dark current, ambient light, and autofluorescence was estimated in control experiments with unloaded retinas and subtracted from the cell's fluorescence measurement. For calcium imaging with the ratiometric indicator fura-2, we computed the ratio of the cell's average fluorescence at 340 to that at $380 \mathrm{~nm}$ 
(F340/F380). For MEQ, decline of baseline due to dye bleaching and leakage was fitted with a linear decay curve and subtracted from the cell's fluorescence (see Zhang et al. 2006b). The index $\Delta F / F$, where $F$ is the fluorescent intensity obtained at baseline (after background subtraction and baseline correction) and $\Delta F$ is the deviation from $\mathrm{F}$ at a given time, was used as a measure of change in $\left[\mathrm{Cl}^{-}\right]_{\mathrm{i}}$. Note that since MEQ fluorescence is quenched collisionally by $\mathrm{Cl}^{-}, \Delta F / F$ goes down proportionally with an increase in $\mathrm{Cl}^{-}$. The intracellular chloride concentration in Ames or Ringer solutions is proportional to the fluorescence change according to

$$
[\mathrm{Cl}]_{\mathrm{i}}=[\mathrm{Cl}]_{\mathrm{ref}}+\frac{\Delta F_{\text {ref }}}{F}\left(K_{50}+[\mathrm{Cl}]_{\mathrm{ref}}\right)
$$

where $F$ is the fluorescence in Ames or Ringer, $\Delta F_{\text {ref }}$ is the difference between equilibrated fluorescence and the initial fluorescence, $K_{50}$ is the half quenching constant obtained from the Stern-Volmer plot, and $\left[\mathrm{Cl}^{-}\right]_{\text {ref }}$ is the equilibrated chloride concentration (Zhang et al. 2006b).

\section{Genotyping}

The NKCC1 knockout mouse was generated in a mixed C57BL6J-DBA/2J background and homozygous animals were obtained from heterozygous breeding (Pace et al. 2000). Genotyping was done by PCR with two sets of primers: one detecting the wild-type NKCC1 allele, the other detecting the mutant NKCC1 allele (neomycin resistant gene cassette). NKCC1 upper primer 5'CGTGTGTTGTTCGGGATGCCA and NKCC1 lower primer 5'GTTGTTCATTAGCCCGTAAGAACA generate 106-bp PCR product. Neo upper primer 5'-ATGGATTGCACGCAGGTTCT and Neo lower primer 5'-CCTTGAGCCTGGCGAACAGT generate 512-bp PCR product.

\section{RES ULTS}

\section{Specificity of antibodies}

Initial experiments to localize NKCC1 were performed with the commonly used $\mathrm{T} 4$ monoclonal antibody raised against human NKCC1 (supplemental Fig. $1 A^{1}$ ). In Western blotting, this antibody recognized a band at the correct $\mathrm{MW}$ (155 kDa), which was eliminated in the NKCC1-null mouse, but it also recognized two prominent bands at 110 and 60 $\mathrm{kDa}$ that were not eliminated in the null mouse supplemental Fig $1 B$. In immunostaining, horizontal cells, which were detected by the T4 antibody when applied to rabbit and monkey (Vardi et al. 2000), were not detected in the mouse. Staining with this antibody was present in dendritic tips of ON bipolar cells (strongly), and in lateral processes in the inner plexiform layer (weakly). However, this staining pattern appeared similar in the NKCC1-null retina (supplemental Fig. 1, $C$ and $D$ ). Further testing revealed that staining of HEK cells transfected with mouse NKCC1 resembled that of untransfected cells (supplemental Fig. 1E). These experiments suggested that the T4 antibody does not recognize mouse NKCC1 under our staining conditions. Consequently, data collected with the T4 antibody were not used.

In contrast, another antibody against NKCC1 (a polyclonal antibody raised against the $\mathrm{C}$-terminus of the mouse protein; sequence is shown in supplemental Fig. 1A) did not stain untransfected HEK cells and gave a membrane-associated staining in cells transfected with NKCC1 (supplemental Fig. 1, $F$ and $G$ ). Western blotting with this antibody gave a doublet at the expected molecular weight $(\sim 150$ kDa; Fig. 1A). Neither band was present in the NKCC1-null retina. Immunostaining of the adult wild-type retina was primarily restricted to horizontal cells, where somas and processes stained strongly (Fig. $1 B$ ); processes of on bipolar cells were unstained (not shown). Immunostaining of the young wild-type retina showed staining throughout the retina (Fig. $1 C$ ). The intensities of both staining patterns, in the adult and young retinas, were diminished in the NKCC1null retinas ( $n>3$; Fig. $1, B$ and $C$ ). Thus the polyclonal anti-NKCC1 is specific and can be used for further localization and quantification. For KCC2, we used an antibody

\footnotetext{
${ }^{1}$ The online version of this article contains supplementary material.
}

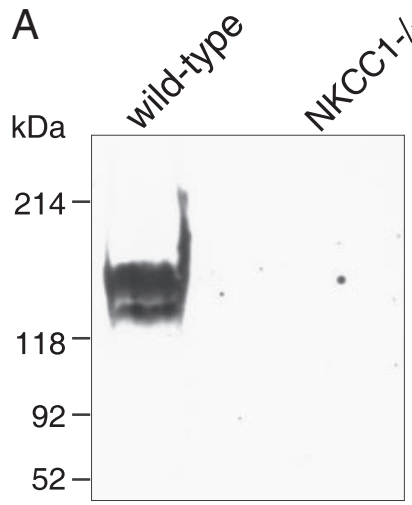

adult

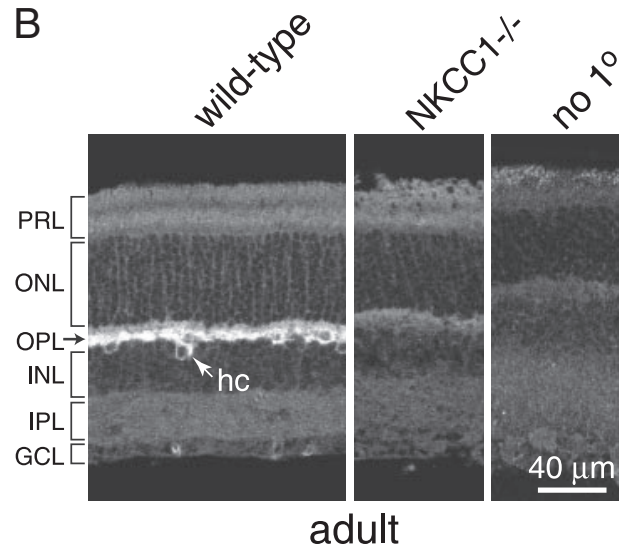

adult

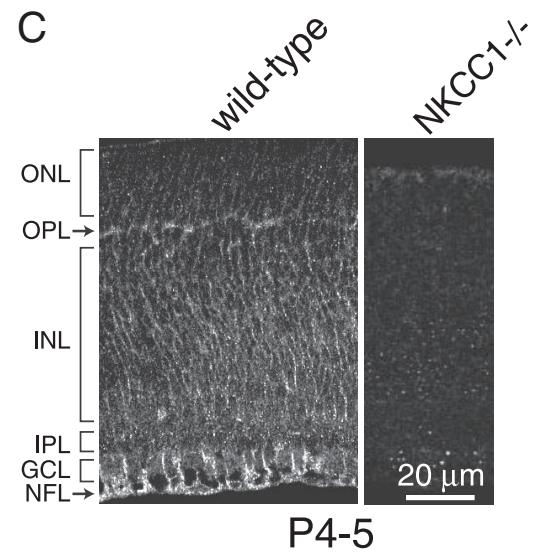

FIG. 1. Polyclonal anti-NKCC1 is specific in retina. A: Western blots of wild-type retina immunoreacted with the polyclonal antibody against NKCC1 shows a doublet $\sim 150 \mathrm{kDa}$, which is absent from the NKCC1-null (-/-) retina. The doublet likely represents NKCC1 protein with different glycosylation levels (Plotkin et al. 1997a,b). B: confocal fluorescence micrograph of vertical adult sections immunostained for NKCC1. Horizontal cells (hc) are strongly stained in wild-type retina but not in NKCC1-null retina. In $B$ and $C$, staining parameters and image acquisition were identical for wild-type and null retinas. PRL, photoreceptor layer; ONL, outer nuclear layer; OPL, outer plexiform layer; INL, inner nuclear layer; IPL, inner plexiform layer; GCL, ganglion cell layer; NFL, nerve fiber layer. $C$ : confocal fluorescence micrograph of vertical juvenile sections (P4-5) immunostained for NKCC1. Staining is present throughout the wild-type retina and is absent from the null retina. No $1^{\circ}$, Primary antibody was omitted. 
that has been established to be specific in rodent retina (Vardi et al. 2000; Vu et al. 2000).

\section{NKCC1 and KCC2 upregulate during development}

In mouse, intracellular chloride concentration decreases at about P6 (Zhang et al. 2006b), so we used Western blots and immunohistochemical staining to map the pattern of chloride cotransporters across $\mathrm{P} 0-24$ aged retinas. Western blots showed that NKCC1 was present as early as $\mathrm{P} 0$, maintained a constant level through $\mathrm{P} 5$, then rapidly increased reaching a plateau between P12 and 24, and finally declined to a much lower adult level (Fig. 2). In contrast, KCC2 was undetectable during $\mathrm{P} 0-5$, clearly visible at $\mathrm{P} 8$, then rapidly increased reaching a peak between P17-24, and finally dropped slightly to the adult level.
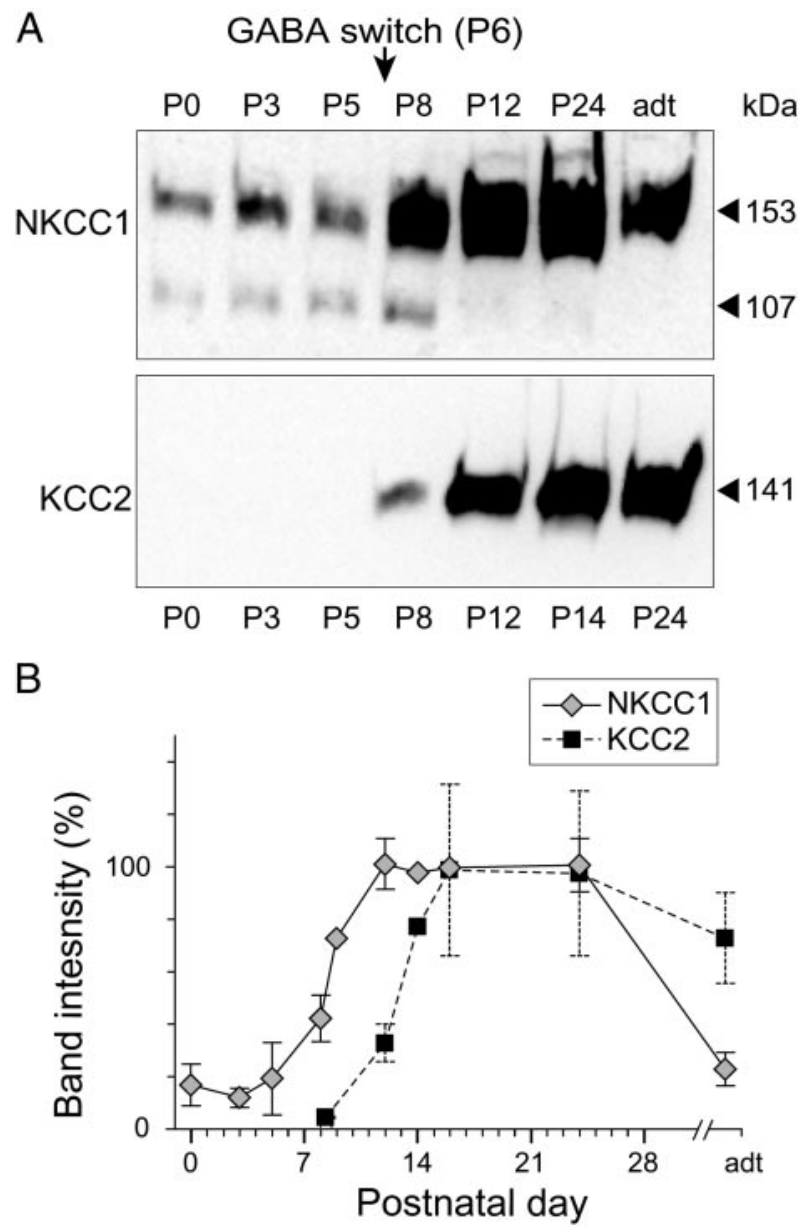

FIG. 2. NKCC1 and KCC2 expression upregulate during postnatal development (Western blots). A: equal amounts of protein homogenate were loaded onto each lane and probed with the antibodies against NKCC1 or KCC2 (both blots are from the same experiment). Arrow, time that GABA switches from depolarizing to hyperpolarizing. Immunoblotting with the antibody against $\mathrm{NKCC} 1$ in the early retina often gave 2 bands, the lower might be a degradation product because it disappears in the NKCC1-null mouse. $B$ : quantification of Western blots for NKCC1 (3 experiments) and KCC2 (4 experiments). Data are from 2 series, but certain dates had representation from only 1 experiment and those do not have error bars; data for KCC2 at P8-9 were binned.
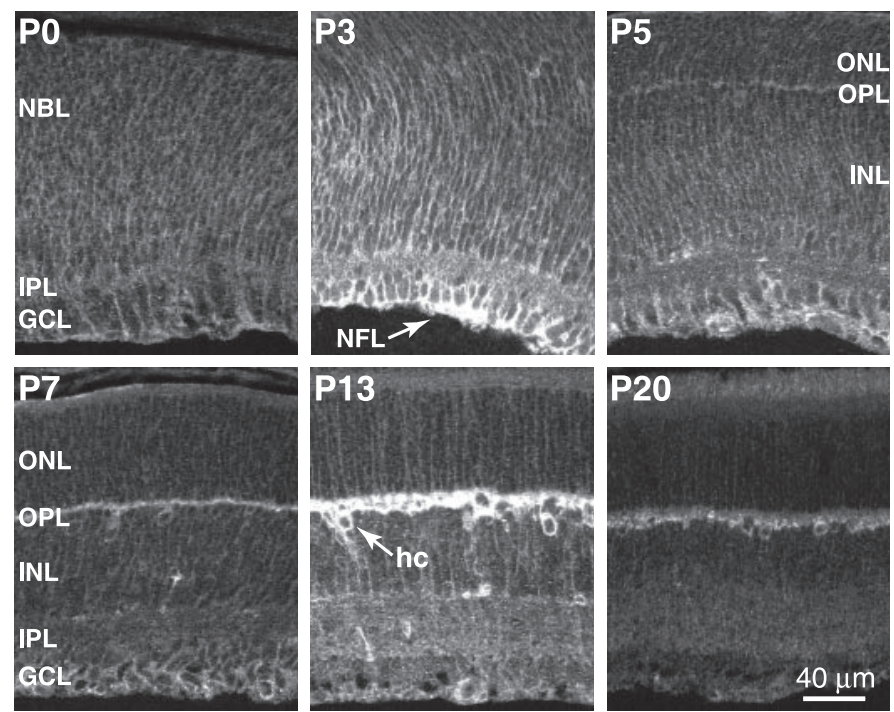

FIG. 3. NKCC1 expression pattern changes during postnatal development (immunohistochemistry). Retinal sections collected from the same litter at different postnatal ages were stained for NKCC1 and then imaged and processed under the same conditions to compare the relative staining intensities. At P0, P3, and P5 retinas, staining for NKCC1 was prominent throughout the retina. At $\mathrm{P} 20$ and onward, staining was almost exclusively restricted to horizontal cell (hc) somas and their processes in the OPL. NBL, neuroblast layer.

NKCC1 expression in the ganglion cell layer is higher in developing retina than in adult

By immunohistochemical staining, NKCC1 was already detected at birth throughout the retina with most somas outlined (Fig. 3). In the inner retina, the ganglion cell layer and the nerve fiber layer just below it were prominently stained by P3; the inner plexiform layer only stained weakly. By P20, staining of the ganglion cell layer and the inner plexiform layer dropped to background levels. In the outer retina, staining for NKCC1 was first detected at P5, the time that this layer becomes distinct. By P7, staining localized to somas and processes at the top of the newly formed inner nuclear layer. On the basis of location and morphological criteria, these appear to belong to horizontal cells. In the following week, staining intensity increased by roughly 2.5 -fold and then declined slightly to the adult level. Thus in the layers where ganglion and amacrine cell somas reside, NKCC1's expression is higher in the early retina than in the adult, consistent with it serving as a chloride accumulator in immature neurons.

\section{KCC2 expression localizes primarily to synaptic layers and increases during development}

Contrary to Western blotting results, immunocytochemistry showed that KCC2 was already detectable at birth (Fig. 4). Apparently immunostaining is more sensitive, possibly because detection in Western blotting is limited by the amount of protein that can be loaded into a lane. The staining at birth was very weak and confined to the developing inner plexiform layer. This staining was punctate, it distributed fairly homogenously throughout the inner plexiform layer, and steadily increased with age. At P7, it became possible to detect the somas of amacrine and ganglion cells. By P10, staining in the inner plexiform separated into two wide bands, roughly corre- 

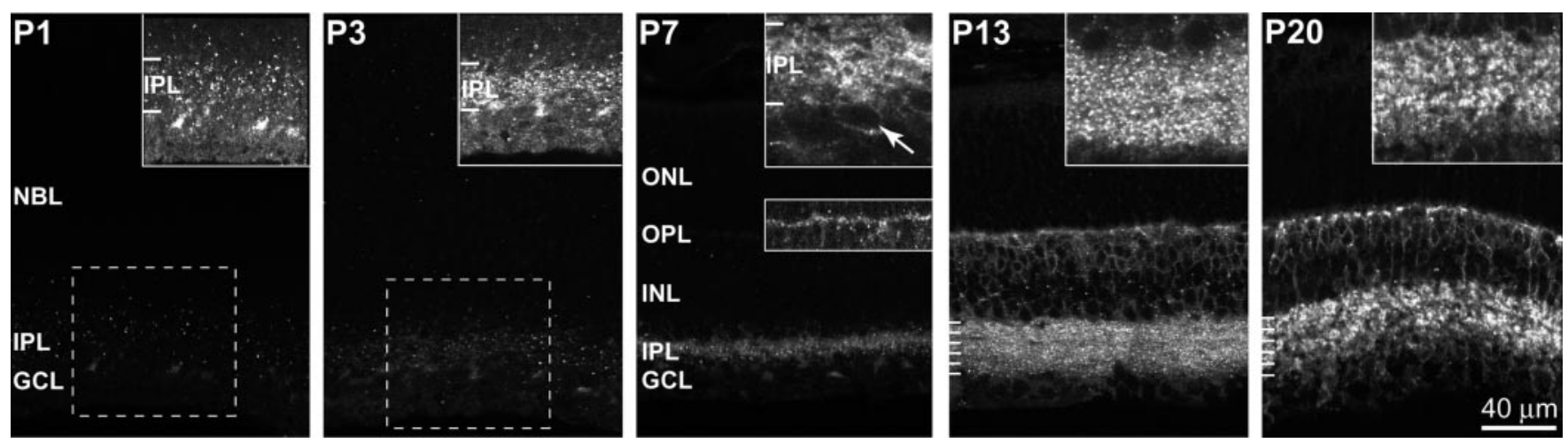

FIG. 4. KCC2 immunoreactivity increases during postnatal maturation. Confocal radial sections from one developmental series immunostained for KCC2. All sections were imaged and displayed with the same parameters. At P0-5, the KCC2 staining was weak and confined to the IPL; at P7, staining was easily detectable in ganglion cell somas; and by P13, it was strong in the OPL, INL, IPL, and GCL. Insets: higher contrast of IPL or OPL. For P1 and P3, the insets were from the area enclosed by - - - . For P7, the IPL inset was taken from a different image to show the stained somas in the GCL ( $\rightarrow$ ), and the OPL inset was placed over its correct location in the low contrast image. For P13 and P20, insets show IPL at twice the magnification to show the punctate nature of the stain.

sponding to the ON and OFF sublayers with a thin band between strata 2 and 3 devoid of staining. Staining for KCC2 in the outer retina was detected as soon as the outer plexiform layer formed (P5-7) and this staining continued to increase with age. This data confirms that KCC2 upregulates during development approximately following the order of differentiation of different cell types, consistent with findings in rat, ferret, and turtle (Leitch et al. 2005; Vu et al. 2000; Zhang et al. 2006a).

\section{NKCC null retina has normal gross morphology and physiology}

To test the effect of NKCC1 on GABA's function and chloride accumulation in early retina, we used an NKCC1null mouse. This mouse is deaf, infertile, impaired in pain perception and in locomotion, and may have compromised olfactory sensation (Delpire et al. 1999; Flagella et al. 1999;
Pace et al. 2000; Reisert et al. 2005; Sung et al. 2000). To evaluate the gross morphology and physiology of the NKCC1-null retina, we performed immunostaining. The lack of NKCC1 expression has been established in the preceding text (Fig. 1). Retinas of the NKCC1-null mouse had a thickness similar to those of wild type and contained all the layers and cell types (Fig. 5). Thus photoreceptors and ofF bipolar cells stained for recoverin, rod bipolar cells stained for PKC, and on bipolar cells stained for $\mathrm{G} \gamma_{13}$ and $\mathrm{G} \alpha_{\mathrm{o}}$, all showed normal densities and stratifications. Similarly, amacrine cells stained for calbindin, GABA, and ChAT, and ganglion cells stained for parvalbumin and neurofilament had normal morphology and stratifications. Müller cells stained with an antibody against glutamine synthetase showed radial processes that, as in the adult, stained strongly in the outer nuclear layer and in their terminals in the nerve fiber
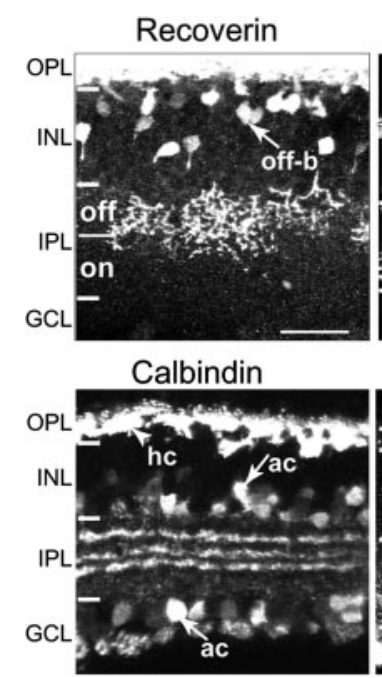

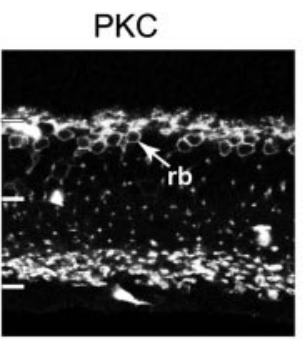

Parvalbumin

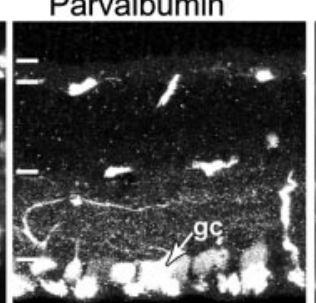

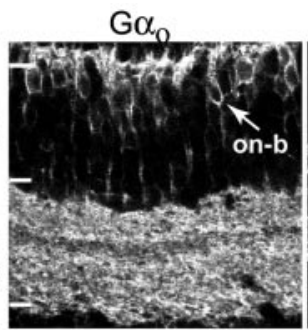

Vimentin

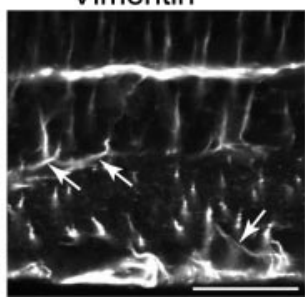

GABA

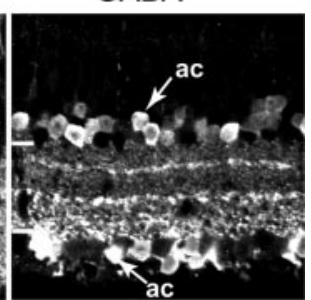

GS

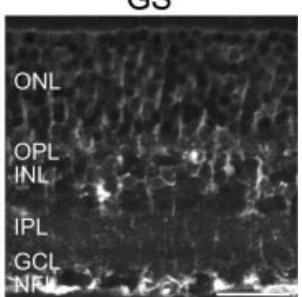

FIG. 5. Gross morphology of NKCC1-null retina is normal. Confocal fluorescence micrograph of adult NKCC1-null retina (vertical sections) stained with different markers. A type of off-bipolar cell (off-b) labeled with anti-recoverin terminated in the off sublamina; the rod bipolar cell (rb) labeled with anti-PKC terminated in sublamina 5 of the IPL; the oN bipolar cells (on-b) labeled with anti-G $\alpha_{\mathrm{o}}$ showed normal high-density up in the INL; the horizontal cell (hc) and amacrine cell (ac) labeled with anti-calbindin had normal appearance with 3 strata in the IPL; the amacrine cells labeled with anti-GABA were numerous in the lower tiers of the INL and more sparse in the GCL; and ganglion cells (gc) labeled with anti-parvalbumin sent processes to all sublaminas of the IPL. Müller cells labeled with vimentin occasionally showed strong processes traveling laterally (arrows). Labeling with glutamine synthetase (GS) showed normal radial processes crossing the retina from the outer limiting membrane to the inner limiting membrane where they terminate as endfeet. Staining for recoverin in the photoreceptor terminals was over-exposed to reveal the staining in off bipolar cells, hence the white area in the OPL. On and off refer to the ON and OFF sublaminas of IPL. Calibration bar: $30 \mu \mathrm{m}$; the bar under recoverin applies to all but vimentin and GS. 

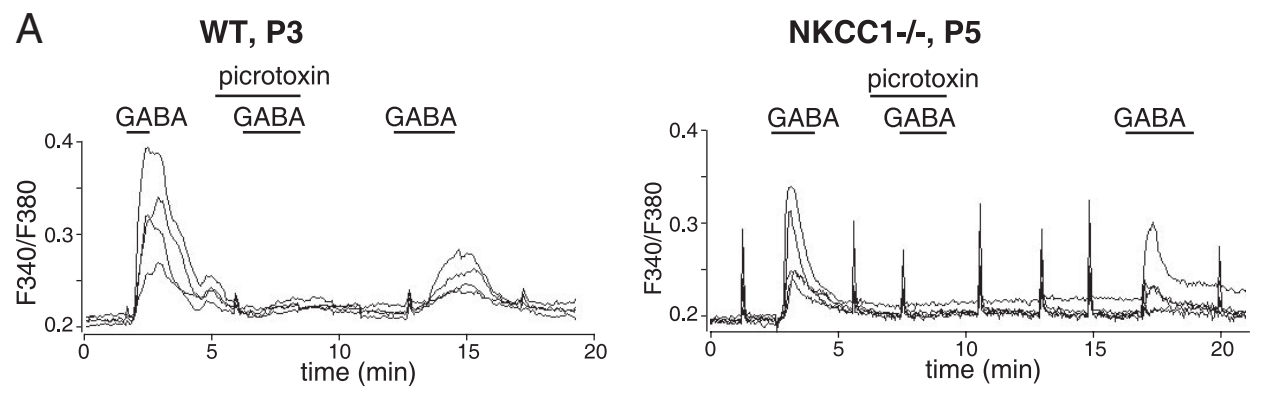

B
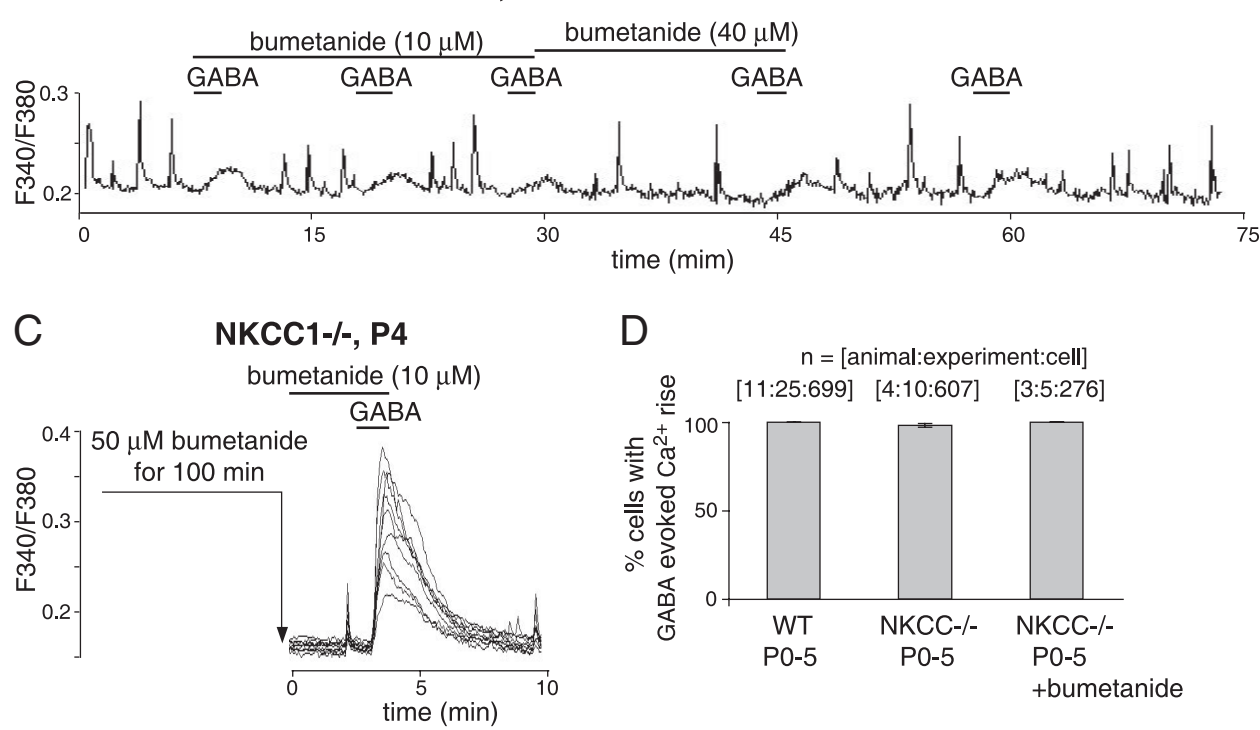

FIG. 6. Inhibiting NKCC1 activity with bumetanide or NKCC1 deletion does not prevent GABA from evoking a $\mathrm{Ca}^{2+}$ rise. Traces show fura-2 fluorescence (ratio of F340/F380) in response to drug applications (indicated by bars); each trace represents a response from a single cell. Spontaneous rhythmic activities of varying sizes were observed in all retinas. A: GABA $(50 \mu \mathrm{M})$ increased intracellular calcium in both wildtype and NKCC1-null retinas. Responses were largely blocked by co-application of the ionotropic GABA receptor antagonist picrotoxin $(50 \mu \mathrm{M})$ and partially recovered after washout. $B$ : bumetanide did not block GABA-evoked calcium rise in $\mathrm{P} 3$ wild-type retina. GABA was used at $150 \mu \mathrm{M}$. C: P4 NKCC1-null retina that was incubated in bumetanide for a long period still showed a calcium rise when exposed to $50 \mu \mathrm{M}$ GABA. $D$ : percentage of cells that show a GABA-evoked calcium rise under various conditions. Percentage was calculated for each experiment and then averaged across experiments. Numbers of animals, experiments, and cells are given in the brackets above each group. Certain error bars are smaller than line size. layer and weakly in the inner plexiform layer. Müller cells with an antibody against vimentin appeared normal in only two of four retinas where strongly stained radial processes crossed the inner plexiform layer and terminated in the nerve fiber layer. In the other two retinas, occasional processes traveled in the inner plexiform layer laterally; this abnormality was never seen in wild type. Physiologically, NKCC1-null retina exhibited normal spontaneous calcium transients during the first postnatal week (see Fig. 6 in the following text). Thus lack of NKCC1 does not affect the gross morphology and physiology of the retina.

\section{NKCC1 deletion and bumetanide application in early ganglion and amacrine cells do not prevent GABA from evoking a $\mathrm{Ca}^{2+}$ rise}

One of the hallmarks of GABA's excitatory action in developing retinal ganglion and amacrine cells is its ability to depolarize cells via chloride efflux, activate voltage-dependent calcium channels, and consequently evoke a rise in intracellular calcium (Zhang et al. 2006b). If NKCC1 accumulates chloride in retinal ganglion and amacrine cells, perturbing its function would lower intracellular chloride concentration to the level of passive distribution, thus abolishing GABA-evoked depolarization and calcium rise. Using fura-2 calcium imaging, we tested the effect of deleting NKCC1 on the GABA-evoked calcium rise in the $\mathrm{P} 0-5$ ganglion cell layer. In both wild-type and NKCC1-null retinas, GABA $(50 \mu \mathrm{M})$ evoked a calcium rise in over $98 \%$ of cells (Fig. 6, $A$ and $D$ ). Because all cells behaved in a similar manner, it is safe to conclude that neither amacrine cells nor ganglion cells of the NKCC1-null retinas were affected. GABA-evoked responses were blocked by the ionotropic GABA receptor antagonist, picrotoxin $(100 \mu \mathrm{M}$; Fig. 6A), suggesting that these responses were due to $\mathrm{GABA}_{\mathrm{A}^{-}}$ mediated chloride currents.

One possible explanation for the lack of a deletion effect is the potential upregulation of another chloride accumulator. We therefore tested the effect of the loop diuretics bumetanide on the GABA-evoked calcium rise. Bumetanide reversibly blocks NKCC (both $\mathrm{NKCC} 1$ and $\mathrm{NKCC} 2$ ) by competing with the second chloride binding site with a half-inhibitory constant of $\sim 0.1 \mu \mathrm{M}$. When used at or $<10$ $\mu \mathrm{M}$, the inhibition is specific for NKCC (Russell 2000); but to ensure full blockade, we used it at 10-50 $\mu \mathrm{M}$. Bumetanide was applied to either wild-type or NKCC1-null retina for up to $40 \mathrm{~min}$ before testing the GABA response. This did not block the GABA-evoked calcium rise (Fig. 6, $B-D$ ). Perhaps intracellular chloride remained high because chloride efflux is slow and the incubation time with bumetanide was not sufficient to reduce it. Thus we facilitated chloride efflux by applying GABA repeatedly and incubating the retina in bumetanide for a longer time (up to $5 \mathrm{~h}$ ), or by incubating the retina in a mixture of bumetanide and GABA. However, neither condition led to a change in response amplitude (Fig. 6, $C$ and $D$ ). Thus neither NKCC1 deletion nor application of NKCC blocker affects GABA's early excitatory action in retinal neurons. 
A WT, P4

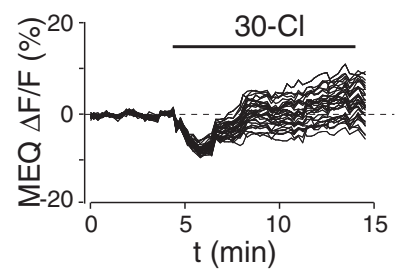

E

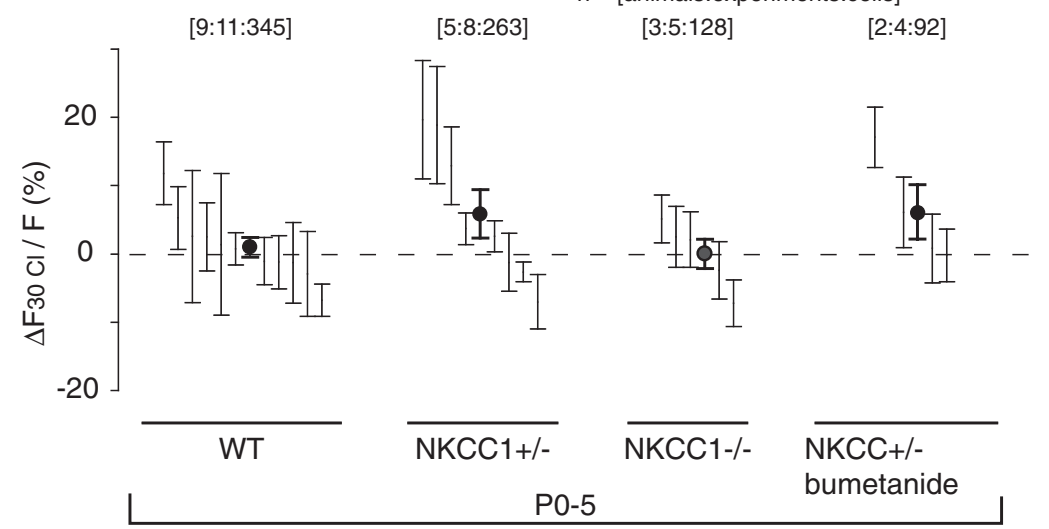

B

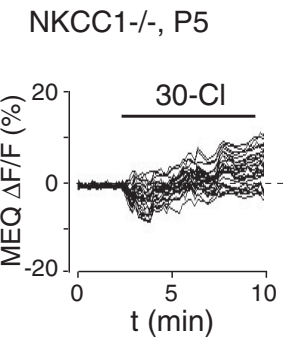

C

WT, P4

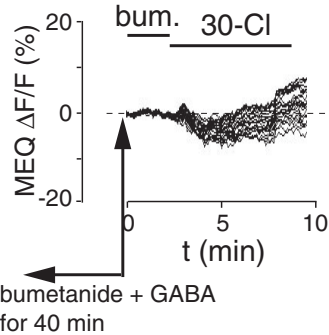

D

WT, P6

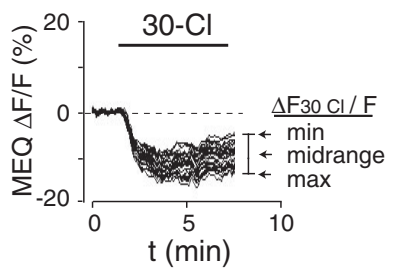

$[3: 5: 138] \quad[4: 4: 77]$

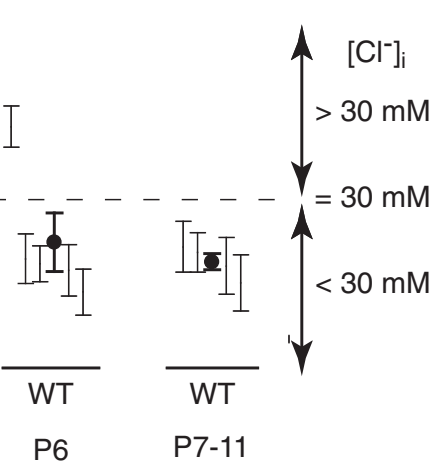

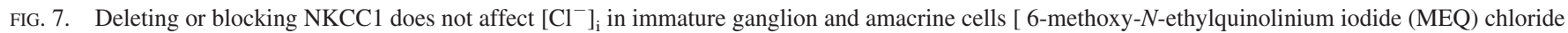

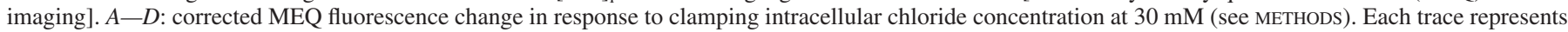

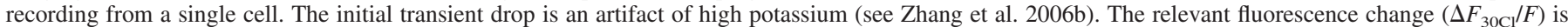

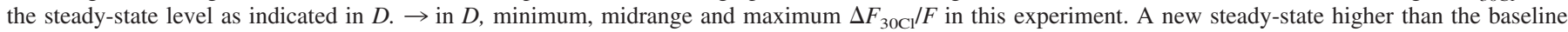

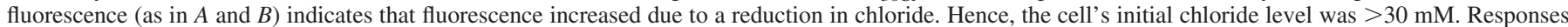

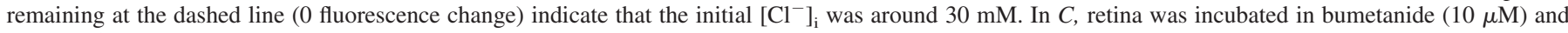

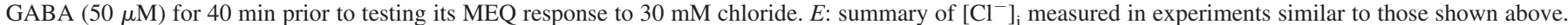

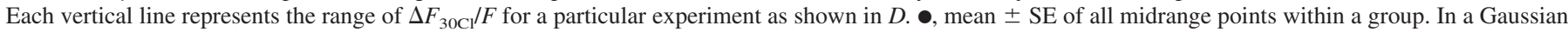

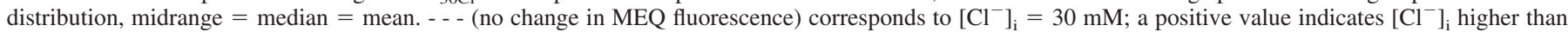
$30 \mathrm{mM}$ and a negative value indicates $\left[\mathrm{Cl}^{-}\right]_{\mathrm{i}}$ lower than $30 \mathrm{mM}$. Numbers of animals, experiments, and cells are given in brackets above each group.

NKCC1 deletion and bumetanide application do not lower intracellular chloride in developing ganglion and amacrine cells

Next, we examined the effect of NKCC1 blockade and deletion on the intracellular chloride concentration itself. Cells in the ganglion cell layer were loaded with the chloride indicator MEQ, and the basal fluorescence with unperturbed chloride concentration was recorded. The retina was then subjected to a reference buffer solution containing $30 \mathrm{mM}$ chloride and the ionophores nigericin and tributyltin to equilibrate chloride across the plasma membrane. Once a new steady state was established, the relative fluorescence change $\Delta F / F$ was proportional to the difference between the reference level $(30 \mathrm{mM})$ and the initial chloride level in the cell (Zhang et al. 2006b). In all three groups, wild-type, heterozygous, and NKCC1-null retinas, the P0-5 retinas exhibited an intracellular chloride concentration around or $>30 \mathrm{mM},(31.1 \pm 1.5$, $36.1 \pm 3.7,30.0 \pm 2.3 \mathrm{mM}$, respectively, $P>0.05$ between each group). In contrast, wild-type P7-11 retinas exhibited intracellular chloride concentrations clearly $<30 \mathrm{mM}(20.3 \pm$ 1.2, $P<0.01$ with each group above), whereas at P6, the transition day, chloride concentration was still close to $30 \mathrm{mM}$ in one retinal piece and reduced to about $20 \mathrm{mM}$ in the rest (Fig. 7). Note that the values given here were calculated from exposing the retinas to a $30 \mathrm{mM}$ reference solution, which is far from the actual intracellular chloride concentration in the wild-type adult retina, and may thus carry a larger error for the adult than the young retinas (Zhang et al. 2006b).

To test the effect of bumetanide, we incubated the retina with this blocker (10 $\mu \mathrm{M}, 40-120 \mathrm{~min})$ with or without GABA (50 $\mu \mathrm{M}$, to facilitate chloride efflux), then added a reference solution of $30 \mathrm{mM}$ chloride and recorded the MEQ fluorescence. In all $\mathrm{P} 0-5$ cells tested, intracellular chloride remained $>30 \mathrm{mM}(36.2 \pm 4.2 \mathrm{mM}, P>0.05$ with the same age groups tested above; Fig. 7, $C$ and $E$ ). To test whether chloride accumulation depends on external sodium levels, we incubated wild-type retina with sodium-free Ringer (substituted with choline) and found that low sodium did not change the corrected baseline fluorescence (not shown) and thus does not affect intracellular chloride. Taken together, the data strongly suggests that neither NKCC1 nor NKCC2 contributes to chloride accumulation in ganglion and amacrine cells in early development.

\section{Early expression of NKCC1 in mouse inner retina appears restricted to Müller cells}

Our finding that NKCC1 is not required for chloride accumulation in the immature ganglion and amacrine cells was 

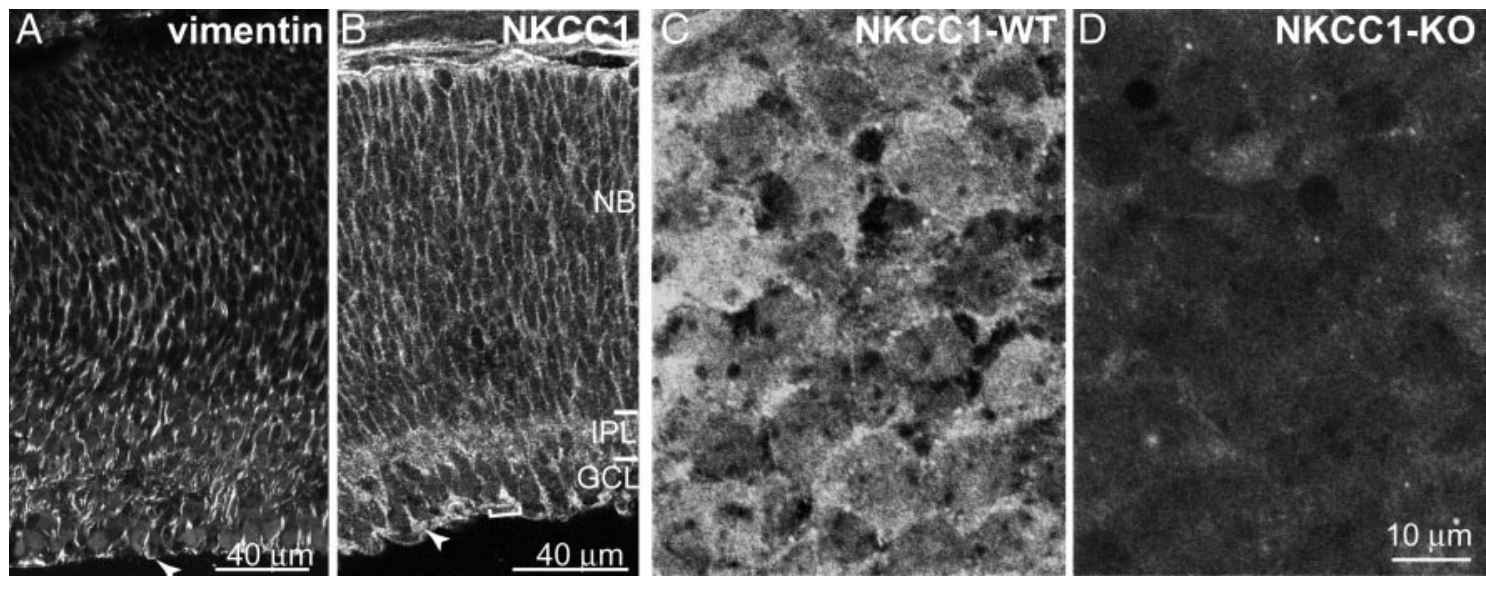

FIG. 8. Staining for NKCC1 in the young retina localizes to Müller cell endfeet. A: immunostaining for vimentin at P3 (radial view) shows radial processes crossing the entire width of the retina with endfeet terminating at the inner limiting membrane (arrowhead). This staining pattern is similar to that in adult retina and primarily represents Müller cell processes (somas are not evident with this marker). B: immunostaining for NKCC1 at P3 is generally similar to that for vimentin with stained endfeet (arrowhead), but the vertical processes in the IPL are not evident by anti-NKCC1 (radial view). Note the punctate staining in the nerve fiber layer (e.g., puncta enclosed by the bracket); these probably correspond to fimbriae. $C$ and $D$ : whole-mount. Immunostaining for NKCC1 at P3 with focus on the nerve fiber layer. Staining in the wild-type $(C)$ carpets the whole layer with much stronger intensity than in the NKCC1-nulll retina $(D)$. Scanning of these retinas was done sequentially with identical parameters.

surprising because it appears inconsistent with the expression profiling that could support the commonly accepted hypothesis that this transporter accumulates chloride in immature neurons. It therefore became essential to examine NKCC1 localization at higher resolution and with specific cell markers. This seemingly simple and crucial experiment proved to be difficult because cells of the young retina don't necessarily express certain markers and staining for the purpose of ultrastructural localization of NKCC1 revealed additional staining (see following text) that incurred by the DAB-intensification method.

First, we wished to test if NKCC1 localizes to ganglion cells using an antibody against neurofilament that marks adult ganglion cells (Haverkamp and Wässle 2000). However, at P3, this antibody rarely gave staining in somas of the ganglion cell layer (not shown). To test if NKCC1 localizes to Müller cells (the processes of which envelop most cells), we used the known markers of these cells, vimentin and glutamine synthetase (Robinson and Dreher 1990; Haverkamp and Wässle 2000). Staining for NKCC1 at P3 looked similar to that for vimentin. It was present in processes that crossed through the nuclear layers, outlined somas, and terminated just below the ganglion cells as "endfeet" (Fig. 8, $A$ and $B$ ). The endfeet were clearly composed of fine processes called fimbriae (Robinson and Dreher 1990). Vertical processes in the inner plexiform layer were not detected by anti-NKCC1. In a whole-mount preparation, when focused on the nerve fiber layer, staining for NKCC1 appeared throughout the layer, consistent with endfeet forming the inner limiting membrane; this staining diminished in the NKCC1-null mouse (Fig. 8, $C$ and $D$ ). When focused on the ganglion cell layer, staining appeared in spaces between somas, similar to staining for vimentin and different from staining for $\mathrm{KCC} 2$ in the adult retina (supplemental Fig. 2, $A-C)$. Double staining for NKCC1 and vimentin was not possible because both antibodies were raised in rabbit.

Double staining for glutamine synthetase (raised in mouse) and NKCC1 showed that these two proteins colocalize in spaces between somas of the ganglion cell layer (Fig. 9, A-C), in vertical Müller cell processes crossing the neuroblast layer, and in Müller cell endfeet located in the nerve fiber layer (Fig.
9, $D-F)$. However, colocalization with glutamine synthetase was not perfect. In particular, a line demarcating the inner limiting membrane was stained for glutamine synthetase but not for NKCC1. This line was not seen with vimentin staining and may represent astrocytes. Thus we labeled astrocytes in a whole-mount retina (where these cells can be viewed best) with an antibody against glia fibrilary acidic protein (GFAP) (Karschin et al. 1986; Vaughan et al. 1990) and found that most astrocytic processes did not co-stain for NKCC1 (Fig. 9, $G-I$ ).

An attempt to examine the stain at the ultrastructural level confirmed the localization to Müller cells and lack of expression by developing neurons. A P3 retina stained for NKCC1 and processed with DAB followed by silver-gold amplification was very dark, yet staining in plastic sections of $0.5-$ to $1.2-\mu \mathrm{m}$ thick appeared too faint. In thicker sections $(1.5 \mu \mathrm{m})$, stain appeared in fan-like structures below the ganglion cells; these appear to be Müller cell endfeet with their convoluted fimbriae (supplementary Fig. 2, $D$ and $E$ ). Strong staining (not detected by fluorescent microscopy) also appeared associated with the nuclear membranes of all somas; but none was associated with the ganglion and amacrine cell plasma membrane. Whether or not the nuclear stain is specific requires further experiments. In summary, our data suggest that NKCC1 is localized to Müller cells but not to the plasma membrane of retinal neurons or astrocytes.

\section{I S C U S S I O N}

\section{Localization of $\mathrm{NKCCl}$ in the adult mouse retina}

Using the specific anti-NKCC1 polyclonal antibody, we report here that staining in the adult was mostly restricted to horizontal cells. The inner plexiform layer stained very weakly, and it is currently not known which processes may express NKCC1. Staining of horizontal cells is in agreement with previous reports in monkey and rabbit (Vardi et al. 2000, 2002). Strikingly, dendritic tips of on bipolar cells stained with the monoclonal T4 antibody (Vardi et al. 2000) remained unstained by the polyclonal antibody used in this study. Be- 

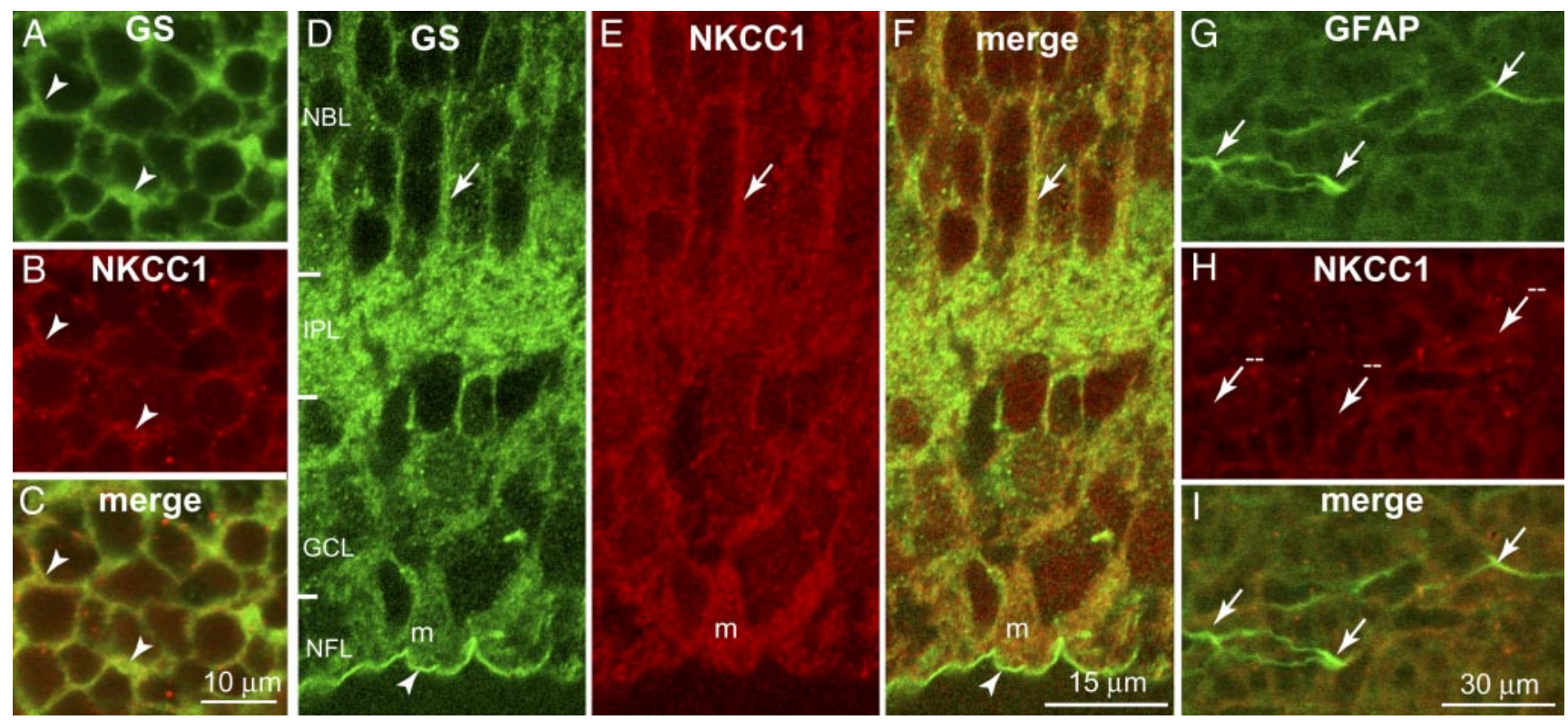

FIG. 9. NKCC1 localizes to Müller cells but not astrocytes. $A-F$ : costaining of radial sections of P3 retina with the Müller cell marker glutamine synthetase (GS; green) and NKCC1 (red). A-C: oblique, almost whole-mount view at the level of ganglion cell layer. Staining for GS and NKCC1 colocalizes in regions between ganglion and amacrine cells (arrowheads). $D-F$ : radial view. Arrows point to a radial process typical of Müller cells. The diffuse staining in the inner plexiform layer in GS may be due to cross reactivity of the secondary antibody with mouse retina aged P0-5. The Müller cell endfeet (m) are NKCC1-positive. A line at or below the inner limiting membrane (arrowhead) is stained for GS but not for NKCC1. $G-I$ : costaining of P3 whole-mount with the astrocyte cell marker GFAP (green) and NKCC1 (red) (whole-mount, focus is on nerve fiber layer). GFAP staining shows long processes (arrows) that are negative for NKCC1 (arrows with a minus sign). In immature retina, the anti-GFAP antibody did not detect somas of astrocytes.

cause the staining obtained with the T4 antibody was similar in wild-type and NKCC1-null mouse, we have to conclude that this staining in mouse does not represent NKCC1. However, because the $\mathrm{T} 4$ antibody was raised against human $\mathrm{NKCC} 1$, its staining in monkey retina may still be valid. Indeed, unlike mouse, monkey retina horizontal cells did stain, and the inner plexiform layer was largely unstained, suggesting that it does not exhibit the same cross-reactivity in monkey as it does in mouse. The polyclonal antibody gave no staining in monkey (unpublished data) or ferret (Zhang et al. 2006a), so the localization of NKCC1 in these species could not be verified. Lack of staining in oN bipolar dendritic tips suggests that mouse ON bipolar dendrites do not express $\mathrm{NKCC} 1$, but it is highly likely that they express an NKCC1-like transporter that is recognized by the T4 antibody. This interpretation is supported by physiological recordings that show that on bipolar dendritic tips have relatively high intracellular chloride concentration, which is not completely diminished by bumetanide (Varela et al. 2005; Duebel et al. 2006).

\section{NKCCl does not accumulate chloride in most immature neurons}

We show here that in the first postnatal week, neither the nature of GABA action nor the intracellular chloride concentration in ganglion and amacrine cells is altered by genetic deletion of NKCC1. It might be proposed that genetic deletion of NKCC1 triggers developmental compensation and upregulation of another protein or mechanism that can maintain a high intracellular chloride. However, pharmacologically blocking NKCC transporter in early wild-type retinas with bumetanide did not alter intracellular chloride concentration either. Furthermore, high-resolution confocal microscopy and electron microscopy does not support NKCC1's presence in plasma membrane of immature retinal neurons.

The extent to which NKCC1 localizes to premature brain neurons is still unclear. In the lateral superior olive, a system where the GABA's switch was rigorously studied, the major neurons during the period of GABA excitation do not express NKCC1 mRNA (Balakrishnan et al. 2003). In cerebellum, NKCC1 mRNA expression originally thought to localize to Purkinje cells (Plotkin et al. 1997a) was later found to localize to the glial cells surrounding the Purkinje cells (Kanaka et al. 2001). Most studies documenting NKCC1 presence in immature neurons were done at a low resolution. To our knowledge, the function of $\mathrm{NKCC} 1$ in normal immature neurons has so far been demonstrated only in certain neocortical neurons (Yamada et al. 2004). Together with the report by Balakrishnan et al. (2003), our data challenge the standing hypothesis that $\mathrm{NKCC} 1$ is the primary chloride accumulator in juvenile neurons. Thus a new accumulator for these cells remains to be found.

\section{Possible candidates for a chloride accumulator in early retinal neurons}

Transporters and exchangers that can accumulate chloride include the kidney-specific $\mathrm{Na}^{+} / \mathrm{Cl}^{-}$cotransporter, the $\mathrm{Na}^{+}$/ $\mathrm{K}^{+} / \mathrm{Cl}^{-}$cotransporter (NKCC), the $\mathrm{Cl}^{-} / \mathrm{HCO}_{3}^{-}$anion exchanger (Boron 2001), pendrin (similar to sulfate transporter, but transports iodine and chloride) (Scott et al. 1999), and possibly certain types of $\mathrm{ClC}$ chloride channels, recently shown to transport $\mathrm{Cl}^{-}$against its thermodynamic gradient (reviewed by Miller 2006). The $\mathrm{Na}^{+} / \mathrm{Cl}^{-}$cotransporter and NKCC 2 are unlikely candidates not only because they were documented to be specific to kidney but also because in our 
experiments, bumetanide did not block chloride accumulation, and sodium-free solution did not affect intracellular chloride concentrations. Also Western blots with two antibodies against NKCC2 were negative in retina (unpublished results).

As for the $\mathrm{Cl}^{-} / \mathrm{HCO}_{3}{ }^{-}$anion exchanger $\mathrm{AE} 3$, its mRNA appears in the lateral superior olive early in development (Becker et al. 2003). In retina, the long splice variant of this exchanger localizes to adult rat Müller cells and the short splice variant to horizontal cells. The long splice variant expressed by Müller cells was detected in Western blots during the first postnatal week, but it upregulates during development, peaking at the adult (Kobayashi et al. 1994). Furthermore, $E_{\mathrm{GABA}}$ measured in bicarbonate- and HEPES-based medium are similar, suggesting bicarbonate may not change $E_{\mathrm{Cl}}$ either (Zhang et al. 2006b). Thus this exchanger is not a likely candidate to accumulate chloride in early ganglion cells. Because the rest of the chloride accumulators have not yet been tested in retina, there is presently no obvious candidate for early retinal cells.

\section{Possible function of transient NKCCl expression in Müller cells}

Expression of NKCC1 in Müller cells is higher in the developing retina than in the adult. Downregulation of NKCC1 was also reported in the vimentin-positive radial glial cells of the ventricular zone of the subcortical brain regions. There, NKCC1 is expressed transiently, peaking at E14.5 and disappearing later at E17-P0 (Li et al. 2002). Thus the transient pattern in mouse Müller cells is not an isolated event. Because the radial glial cells are neuron progenitor cells (Noctor et al. 2001), Li et al. (2002) proposed that NKCC1 might regulate cell cycle-related volume change. However, in retina, developing Müller cells are not known to be progenitor cells with the exception of chicken Müller cells that have been implicated in neural regeneration in response to acute damage (Fischer and Reh 2003).

Here we propose an alternative hypothesis that links expression of NKCC1 in Müller cells to GABA excitation in juvenile retina. This hypothesis is based on observation in the adult brain, in which GABA applied to hippocampal pyramidal cells changes extracellular chloride concentrations, and this change can be blocked by bicucullin (Muller et al. 1989). This, together with evidence that cortical glial cells express $\mathrm{GABA}_{\mathrm{A}}$ receptors and display a relatively high intracellular chloride concentration of $\sim 40 \mathrm{mM}$, prompted a suggestion that a delayed activation of the $\mathrm{GABA}_{\mathrm{A}}$ receptors on the glial cells would cause a chloride efflux that would raise the extracellular chloride concentration back to normal (Bormann and Kettenmann 1988; MacVicar et al. 1989).

If in retina, as in brain, extracellular chloride concentration changes with extensive activation of $\mathrm{GABA}_{\mathrm{A}}$ receptors located on the neurons, then buffering mechanism may be required. We suggest that NKCC1 expressed by Müller cells can contribute to such buffering of extracellular chloride in the developing retina. When a $\mathrm{GABA}_{\mathrm{A}}$ channel opens, chloride flows out of the cell and temporarily raises extracellular chloride concentration. This activates NKCC1, which transports the chloride into the Müller cell, thus removing excess of chloride from the extracellular space. Müller cells are ideally positioned to buffer extracellular contents with their intimate interaction with neurons, their radial processes that can serve as a pipeline, and their expanded endfeet that could siphon the chloride into the vitreous humor. As NKCC1 takes up chloride into Müller cells, it could also remove excess potassium from the extracellular space, another potentially hazardous byproduct of neuronal excitation, and thus efficiently maintain a healthy microenvironment. A role for NKCC1 in clearing extracellular potassium was also proposed in cerebral ischemia (Chen and Sun 2005). Because the challenge of extracellular chloride accumulation occurs only in early retinal development when GABA causes chloride efflux, the expression of NKCC1 in Müller cells is necessary only transiently.

\section{A C K N OW LE D G M EN T S}

We thank Beverly Koller and Amy Pace for donating the NKCC1-null mouse; Marie Fina, Jian Li, and Michelle Wallenstein for technical assistance; the Penn Neuroscience Graduate Group for its continuing support, and Dr. Rukmini Rao for reading and editing the manuscript. For antibody donations we thank: Mark Knepper (NKCC2), Virginia Lee (vimentin and GFAP), Robert Margolskee (G $\gamma 13$ ), and Alexander Dizhoor (recoverin).

\section{G R A N T S}

This work was supported by National Institutes of Health Grants EY-11105 to N. Vardi and NS-36758 to E. Delpire.

\section{REFEREN CES}

Balakrishnan V, Becker M, Lohrke S, Nothwang HG, Guresir E, Friauf E. Expression and function of chloride transporters during development of inhibitory neurotransmission in the auditory brainstem. J Neurosci 23: 4134-4145, 2003.

Becker M, Nothwang HG, Friauf E. Differential expression pattern of chloride transporters NCC, NKCC2, KCC1, KCC3, KCC4, and AE3 in the developing rat auditory brain stem. Cell Tissue Res 312: 155-165, 2003.

Ben Ari Y. Developing networks play a similar melody. Trends Neurosci 24: 353-360, 2001.

Ben Ari Y. Excitatory actions of GABA during development: the nature of the nurture. Nat Rev Neurosci 3: 728-739, 2002.

Bormann J, Kettenmann H. Patch-clamp study of gamma-aminobutyric acid receptor Cl- channels in cultured astrocytes. Proc Natl Acad Sci USA 85: 9336-9340, 1988.

Boron WF. Sodium-coupled bicarbonate transporters (online). J Pancreas 2: 176-181, 2001.

Catsicas M, Mobbs P. GABAb receptors regulate chick retinal calcium waves. J Neurosci 21: 897-910, 2001.

Chen H, Sun D. The role of Na-K-Cl co-transporter in cerebral ischemia. Neurol Res 27: 280-286, 2005.

DeFazio RA, Keros S, Quick MW, Hablitz JJ. Potassium-coupled chloride cotransport controls intracellular chloride in rat neocortical pyramidal neurons. J Neurosci 20: 8069-8076, 2000.

Delpire E, Lu J, England R, Dull C, Thorne T. Deafness and imbalance associated with inactivation of the secretory $\mathrm{Na}-\mathrm{K}-2 \mathrm{Cl}$ co-transporter. $\mathrm{Na}$ ture Genetics 22: 192-195, 1999.

Duebel J, Haverkamp S, Schleich W, Feng G, Augustine GJ, Kuner T, Euler T. Two-photon imaging reveals somatodendritic chloride gradient in retinal ON-type bipolar cells expressing the biosensor Clomeleon. Neuron 49: 81-94, 2006.

Dzhala VI, Talos DM, Sdrulla DA, Brumback AC, Mathews GC, Benke TA, Delpire E, Jensen FE, Staley KJ. NKCC1 transporter facilitates seizures in the developing brain. Nat Med 11: 1205-1213, 2005.

Fischer AJ, Reh TA. Potential of Muller glia to become neurogenic retinal progenitor cells. Glia 43: 70-76, 2003.

Fischer KF, Lukasiewicz PD, Wong RO. Age-dependent and cell classspecific modulation of retinal ganglion cell bursting activity by GABA. J Neurosci 18: 3767-3778, 1998.

Flagella M, Clarke LL, Miller ML, Erway LC, Giannella RA, Andringa A, Gawenis LR, Kramer J, Duffy JJ, Doetschman T, Lorenz JN, Yamoah EN, Cardell EL, Shull GE. Mice lacking the basolateral Na-K-2Cl cotransporter have impaired epithelial chloride secretion and are profoundly deaf. J Biol Chem 274: 26946-26955, 1999.

Fukuda A, Tanaka M, Yamada Y, Muramatsu K, Shimano Y, Nishino H. Simultaneous optical imaging of intracellular $\mathrm{Cl}^{-}$in neurons in different 
layers of rat neocortical slices: advantages and limitations. Neurosci Res 32: 363-371, 1998.

Gulacsi A, Lee CR, Sik A, Viitanen T, Kaila K, Tepper JM, Freund TF. Cell type-specific differences in chloride-regulatory mechanisms and GABA(A) receptor-mediated inhibition in rat substantia nigra. $J$ Neurosci 23: 8237-8246, 2003.

Haverkamp S, Wässle H. Immunocytochemical analysis of the mouse retina. J Comp Neurol 424: 1-23, 2000.

Hubner CA, Stein V, Hermans-Borgmeyer I, Meyer T, Ballanyi K, Jentsch TJ. Disruption of KCC2 reveals an essential role of K-Cl cotransport already in early synaptic inhibition. Neuron 30: 515-524, 2001.

Ikeda M, Toyoda H, Yamada J, Okabe A, Sato K, Hotta Y, Fukuda A. Differential development of cation-chloride cotransporters and $\mathrm{Cl}^{-}$homeostasis contributes to differential GABAergic actions between developing rat visual cortex and dorsal lateral geniculate nucleus. Brain Res 984: $149-159,2003$

Jarolimek W, Lewen A, Misgeld U. A furosemide-sensitive $\mathrm{K}^{+}$-Cl- cotransporter counteracts intracellular $\mathrm{Cl}^{-}$accumulation and depletion in cultured rat midbrain neurons. J Neurosci 19: 4695-4704, 1999.

Kanaka C, Ohno K, Okabe A, Kuriyama K, Itoh T, Fukuda A, Sato K. The differential expression patterns of messenger RNAs encoding $\mathrm{K}-\mathrm{Cl}$ cotransporters $(\mathrm{KCC} 1,2)$ and $\mathrm{Na}-\mathrm{K}-2 \mathrm{Cl}$ cotransporter $(\mathrm{NKCC} 1)$ in the rat nervous system. Neuroscience 104: 933-946, 2001.

Karschin A, Wässle H, Schnitzer J. Shape and distribution of astrocytes in the cat retina. Invest Ophthalmol Vis Sci 27: 828-831, 1986.

Kobayashi S, Morgans CW, Casey HR, Kopito RR. AE3 anion exchanger isoforms in the vertebrate retina: developmental regulation and differential expression in neurons and glia. J Neurosci 14: 6266-6279, 1994.

Krapf R, Berry CA, Verkman AS. Estimation of intracellular chloride activity in isolated perfused rabbit proximal convoluted tubules using a fluorescent indicator. Biophys J 53: 955-962, 1988.

Leitch E, Coaker J, Young C, Mehta V, Sernagor E. GABA type-A activity controls its own developmental polarity switch in the maturing retina. J Neurosci 25: 4801-4805, 2005.

Li H, Tornberg J, Kaila K, Airaksinen MS, Rivera C. Patterns of cationchloride cotransporter expression during embryonic rodent CNS development. Eur J Neurosci 16: 2358-2370, 2002.

Lu J, Karadsheh M, Delpire E. Developmental regulation of the neuronalspecific isoform of $\mathrm{K}-\mathrm{Cl}$ cotransporter $\mathrm{KCC} 2$ in postnatal rat brains. $\mathrm{J} \mathrm{Neu}$ robiol 39: 558-568, 1999.

MacVicar BA, Tse FW, Crichton SA, Kettenmann H. GABA-activated $\mathrm{Cl}^{-}$ channels in astrocytes of hippocampal slices. J Neurosci 9: 3577-3583, 1989.

Mikawa S, Wang C, Shu F, Wang T, Fukuda A, Sato K. Developmental changes in KCC1, KCC2 and NKCC1 mRNAs in the rat cerebellum. Brain Res Dev Brain Res 136: 93-100, 2002.

Miller C. $\mathrm{ClC}$ chloride channels viewed through a transporter lens. Nature 440: 484-489, 2006

Muller W, Misgeld U, Lux HD. Gamma-aminobutyric acid-induced ion movements in the guinea pig hippocampal slice. Brain Res 484: 184-191, 1989.

Noctor SC, Flint AC, Weissman TA, Dammerman RS, Kriegstein AR. Neurons derived from radial glial cells establish radial units in neocortex. Nature 409: 714-720, 2001.

Pace AJ, Lee E, Athirakul K, Coffman TM, O'Brien DA, Koller BH. Failure of spermatogenesis in mouse lines deficient in the $\mathrm{Na}(+)-\mathrm{K}(+)-$ 2Cl(-) cotransporter. J Clin Invest 105: 441-450, 2000.

Payne JA, Stevenson TJ, Donaldson LF. Molecular characterization of a putative $\mathrm{K}-\mathrm{Cl}$ cotransporter in rat brain. A neuronal-specific isoform. J Biol Chem 271: 16245-16252, 1996.

Plotkin MD, Kaplan MR, Peterson LN, Gullans SR, Hebert SC, Delpire E. Expression of the $\mathrm{Na}(+)-\mathrm{K}(+)-2 \mathrm{Cl}-$ cotransporter $\mathrm{BSC} 2$ in the nervous system. Am J Physiol 272: t-83, 1997a.
Plotkin MD, Snyder EY, Hebert SC, Delpire E. Expression of the Na-K-2Cl cotransporter is developmentally regulated in postnatal rat brains: a possible mechanism underlying GABA's excitatory role in immature brain. $J$ Neurobiol 33: 781-795, 1997b.

Reisert J, Lai J, Yau KW, Bradley J. Mechanism of the excitatory $\mathrm{Cl}^{-}$ response in mouse olfactory receptor neurons. Neuron 45: 553-561, 2005.

Rivera C, Voipio J, Payne JA, Ruusuvuori E, Lahtinen H, Lamsa K, Pirvola U, Saarma M, Kaila K. The $\mathrm{K}^{+} / \mathrm{Cl}$ - co-transporter $\mathrm{KCC} 2$ renders GABA hyperpolarizing during neuronal maturation. Nature 397: 251-255, 1999.

Robinson SR, Dreher Z. Müller cells in adult rabbit retinae: morphology, distribution and implications for function and development. J Comp Neurol 292: $178-192,1990$.

Rohrbough J, Spitzer NC. Regulation of intracellular $\mathrm{Cl}^{-}$levels by $\mathrm{Na}(+)-$ dependent $\mathrm{Cl}^{-}$cotransport distinguishes depolarizing from hyperpolarizing $\mathrm{GABA}_{\mathrm{A}}$ receptor-mediated responses in spinal neurons. J Neurosci 16: 82-91, 1996.

Russell JM. Sodium-potassium-chloride cotransport. Physiol Rev 80: 211276, 2000.

Scott DA, Wang R, Kreman TM, Sheffield VC, Karniski LP. The Pendred syndrome gene encodes a chloride-iodide transport protein. Nat Genet 21: 440-443, 1999.

Sernagor E, Young C, Eglen SJ. Developmental modulation of retinal wave dynamics: shedding light on the GABA saga. J Neurosci 23: 7621-7629, 2003

Stellwagen D, Shatz CJ, Feller MB. Dynamics of retinal waves are controlled by cyclic AMP. Neuron 24: 673-685, 1999.

Sung KW, Kirby M, McDonald MP, Lovinger DM, Delpire E. Abnormal $\mathrm{GABA}_{\mathrm{A}}$ receptor-mediated currents in dorsal root ganglion neurons isolated from Na-K-2Cl cotransporter null mice. J Neurosci 20: 7531-7538, 2000.

Vardi N, Dhingra A, Zhang LL, Lyubarsky A, Wang TL, Morigiwa K. Neurochemical organization of the first visual synapse. Keio J Med 51: $154-164,2002$.

Vardi N, Zhang LL, Payne JA, Sterling P. Evidence that different cation chloride cotransporters in retinal neurons allow opposite responses to GABA. J Neurosci 20: 7657-7663, 2000.

Varela C, Blanco R, de la Villa P. Depolarizing effect of GABA in rod bipolar cells of the mouse retina. Vision Res 45: 2659-2667, 2005.

Vaughan DK, Erickson PA, Fisher SK. Glial fibrillary acidic protein (GFAP) immunoreactivity in rabbit retina: effect of fixation. Exp Eye Res 50: 385-392, 1990.

Vu TQ, Payne JA, Copenhagen DR. Localization and developmental expression patterns of the neuronal $\mathrm{K}-\mathrm{Cl}$ cotransporter $(\mathrm{KCC} 2)$ in the rat retina. J Neurosci 20: 1414-1423, 2000.

Williams JR, Sharp JW, Kumari VG, Wilson M, Payne JA. The neuronspecific $\mathrm{K}-\mathrm{Cl}$ cotransporter, $\mathrm{KCC} 2$ : antibody development and initial characterization of the protein. J Biol Chem 274: 12656-12664, 1999

Yamada J, Okabe A, Toyoda H, Kilb W, Luhmann HJ, Fukuda A. $\mathrm{Cl}^{-}$ uptake promoting depolarizing GABA actions in immature rat neocortical neurons is mediated by NKCC1. J Physiol 557: 829-841, 2004.

Zhang LL, Fina ME, Vardi N. Regulation of KCC2 and NKCC during development: membrane insertion and differences between cell types. J Comp Neurol 499: 132-143, 2006a.

Zhang LL, Pathak HR, Coulter DA, Freed MA, Vardi N. Shift of intracellular chloride concentration in ganglion and amacrine cells of developing mouse retina. J Neurophysiol 95: 2404-2416, 2006b.

Zhou ZJ. A critical role of the strychnine-sensitive glycinergic system in spontaneous retinal waves of the developing rabbit. J Neurosci 21: 5158 5168,2001

Zhu L, Lovinger D, Delpire E. Cortical neurons lacking KCC2 expression show impaired regulation of intracellular chloride. J Neurophysiol 93: 1557-1568, 2005. 
sFig. 1. Test of antibodies against NKCC1.

A. An alignment between mouse NKCC1 and human NKCC1 at the C-terminus. Yellow, sequence used for generating the monoclonal antibody T4; blue, sequence used to generate the polyclonal antibody, bold and underlined, exon 21 which is spliced out in NKCC1b.

B. Western blots of wild type retina immunoreacted with the T4 monoclonal antibody shows a band at $155 \mathrm{kDa}$, which is absent from the NKCC1-null (-/-) retina and another prominent band at around $110 \mathrm{kDa}$, which remains in the NKCC1-null retina (Plotkin et al. 1997b).

C, D. Immunostaining with the T4 antibody of wild type (C) and NKCC1-null (D) retinas. Staining in the null retina is weaker than in the wild type, but the staining pattern is similar. Stain is strong in puncta corresponding to dendritic tips of ON bipolar cells and not detected in horizontal cells somas. bv, blood vessel.

E-G. Human embryonic kidney (HEK) cells were cotransfected with mouse NKCC1 (NKCC1a or NKCC1b splice variants) and GFP, and then tested either with the T4 monoclonal antibody or with the rabbit polyclonal antibody against mouse NKCC1 (pa).

E. Transfected with NKCC1a, immunostained with T4. This antibody gave staining in all cells, and transfected cells (green) did not stain more strongly than untransfected. Staining in untransfected cells may be due to endogenous expression of NKCC (NKCC1 or NKCC2) by HEK cells, but it is also possible that the staining is non-specific. Similar staining was obtained in COS cells (not shown). The fact that transfected cells did not stain stronger than untransfected suggests that the T4 antibody does not recognize mouse NKCC1 under our fixation conditions.

F, G. Transfected with NKCC1a (E) or NKCC1b (F), immunostained with the polyclonal antibody. All GFP-expressing cells also immunostained for NKCC1 suggesting that this antibody recognizes both splice variants of mouse NKCC1. In this merged display, some cells that immunostain with the antibody appear to lack GFP, but this is an artifact of the display; these cells did show light GFP expression. The fact that untransfected cells did not stain with this antibody suggests either that NKCC1 is not endogenously expressed by HEK cells, or that the polyclonal antibody against mouse NKCC1 does not recognize human NKCC1. These possibilities cannot be resolved at the moment, but it is safe to conclude that the polyclonal antibody is specific for mouse NKCC1 and is a better antibody than T4 to label this protein. Scale bar in E refers also to $\mathrm{F}$ and $\mathrm{G}$.

sFig. 2. Müller cells, but not ganglion cell membrane, stain for NKCC1.

A-C. Confocal fluorescent images of whole mount retina with the focus on the ganglion cell layer. A. Staining for KCC2 in the adult mouse. Staining appears to encircle ganglion cell somas $(*)$, consistent with this transporter being localized to the plasma membrane of ganglion cells. B. Staining for vimentin (known to stain Müller cells) at P3. This stain is strongest in triangular structures (arrowheads) filling the space between ganglion cell somas. C. Staining for NKCC1 at P3. Similar to staining for vimentin, anti-NKCC1 stains triangular structures (arrowheads) likely located between ganglion cell somas.

D-F. P3 mouse, staining was developed with DAB reaction product amplified with silver and gold.

D, E. Radial plastic sections (1.5 $\mu \mathrm{m}$ thick) viewed under differential interference contrast. D. A control section in which the primary antibody was omitted. E. Staining for NKCC1. Faint stain is seen in a Müller cell process (arrow, m) between ganglion cell somas $\left({ }^{*}\right)$ and in its endfeet (arrow, ef). Stain is also seen associated with the nuclear membrane (arrowhead), but not with the ganglion cell plasma membrane (double arrowhead). F. Electron micrograph showing a small region of a ganglion cell soma with its nucleus (nu) and cytoplasm (cy). Stain is associated with the nuclear membrane (arrowhead) but not with plasma membrane of the ganglion cell (double arrowhead). A single gold particle is also seen in a process nearby that 
appears to belong to a Müller cell. Most Müller cell processes were disrupted and could not be identified in the electron micrographs. It is unclear whether staining in the nucleus is specific as it is not seen by fluorescent microscopy and the EM was not repeated on the NKCC1-null mouse. 
DTCKSSGEKSITQKDEEEDGKTPTQPLLKKESKGPIVPLNVADQKLLEASTQFQKKQGK DT $K$ EK IT K EEEDGKT TOPLLKKESKGPIVPLNVADOKLLEASTOFOKKOGK

963 DTSKPLSEKPITHKVEEEDGKTATOPLLKKESKGPIVPLNVADOKLLEASTOFOKKOGK

1016 TIDVWWLFDDGGLTLLIPYLLTTKKKWKDCKIRVF IGGKINRIDHDRRAMATLLSKFRI TIDVWWLFDDGGLTLLI PYLLTTKKKWKDCKIRVF IGGKINRIDHDRRAMATLLSKFRI

1023 TIDVWWLFDDGGLTLLIPYLLTTKKKWKDCKIRVFIGGKINRIDHDRRAMATLLSKFRI

1076 FSDIMVLGDINTKPKKENI IAYDDMIEPYRLHEDDKEQDIADKMKEDEPWRITDNELEL FSD IMVLGD INTKPKKENI IA ++++ IEPYRLHEDDKEODIADKMKEDEPWRITDNELEL

1083 FSDIMVLGDINTKPKKENI IAFEEI I PPYRLHEDDKEQDIADKMKEDEPWRITDNELEL

1136 KTKTYRQIRLNELLKEHSSTANI IVMSLPVARKGAVSSALYMAWLEALSKDLPPVLLVR KTKTYROIRLNELLKEHSSTANI IVMSLPVARKGAVSSALYMAWLEALSKDLPP+LLVR

1143 KTKTYRQIRLNELLKEHSSTANI IVMSLPVARKGAVSSALYMAWLEALSKDLPPILLVR

1196 NHQSVLTFYS 1205 NHOSVLTFYS

1203 NHOSVLTFYS 1212

B

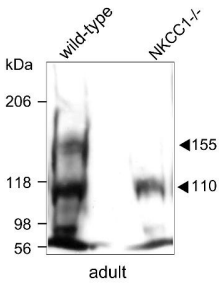

C

C

T4 WT

D

T4 NKCC1-KO

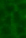

ONL

5

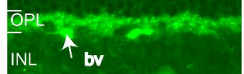

s.
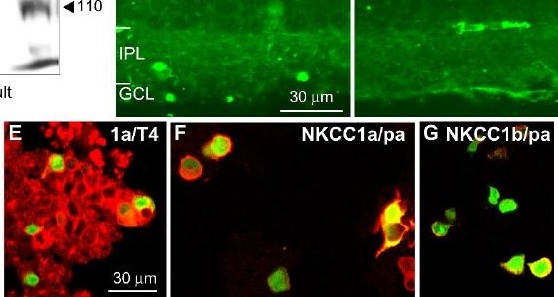
